\title{
An Update on Aptamer-Based Multiplex System Approaches for the Detection of Common Foodborne Pathogens
}

\author{
Omar Mukama ${ }^{1,2}$ - Jean Paul Sinumvayo ${ }^{1}$ - Muhammad Shamoon ${ }^{3}$. \\ Muhammad Shoaib $^{3}$ - Henriette Mushimiyimana ${ }^{1}$ - Waseem Safdar ${ }^{3}$ - Leo Bemena ${ }^{1}$. \\ Peter Rwibasira $^{2} \cdot$ Samson Mugisha $^{1} \cdot$ Zhouping Wang $^{3}$
}

Received: 16 September 2016/Accepted: 11 January 2017

(C) Springer Science+Business Media New York 2017

\begin{abstract}
Foodborne ailments constitute a public health challenge and pose an incredible economic burden in healthcare system around the globe. This dilemma has urged authorities and other entities working in field of food quality control and supply chain to play a pivotal role in ensuring food safety. Analytical strategies have been developed using numerous systematic evolution of ligands by exponential enrichment (SELEX) methods to assure food safety. High-affinity and high-sensitivity ssDNA and RNA aptamers against pathogens have emerged as a novel strategy, as compared to the more resource-demanding and complicated biochemical test-based approaches. Thus, this review aims to focus on some methods used in the selection of specific bare, modified, and conjugated aptamers and on the further analysis of selected aptamers using flow cytometer or post-SELEX modifications for enhanced detection of frequently diagnosed foodborne bacteria such as Bacillus sp., Campylobacter jejuni, Escherichia sp., Salmonella sp., Staphylococcus aureus, Shigella sp., Listeria monocytogenes, and Streptococcus pyogenes and/or targeting
\end{abstract}

Omar Mukama

momary05@yahoo.fr

Zhouping Wang

wangzp@jiangnan.edu.cn

1 Key Laboratory of Carbohydrate Chemistry and Biotechnology, School of Biotechnology, Jiangnan University, Wuxi 214122, People's Republic of China

2 Department of Applied Biology, College of Science and Technology University of Rwanda, Avenue de l'armée, P.O. Box: 3900, Kigali, Rwanda

3 State Key Laboratory of Food Science and Technology, School of Food Science and Technology, Synergetic Innovation Center of Food Safety and Nutrition, Jiangnan University, Wuxi 214122, People's Republic of China their cell components towards attaining fast, sensitive, and selective methods for the detection of pathogens in food(s) or other sources.

Keywords Aptamers $\cdot$ Modified SELEX $\cdot$ Foodborne pathogens $\cdot$ Food safety

$\begin{array}{ll}\text { Abbreviations } & \\ \text { FAM } & \text { 6-Carboxyfluorescein } \\ \text { ATCC } & \text { American Type Culture Collection } \\ \text { FluMag- } & \text { Aptamer fluorescent labeling and magnetic } \\ \text { SELEX } & \text { beads immobilization } \\ \text { AM-ECL } & \text { Aptamer-magnetic bead- } \\ & \text { electrochemiluminescence } \\ \text { CE } & \text { Capillary electrophoresis-SELEX } \\ \text { CDC } & \text { Centers for Disease Control and Prevention } \\ \text { dPa } & \text { Deoxyribonucleoside triphosphate } \\ \text { Px } & \text { 4-propynylpyrrole-2-carbaldehyde } \\ \text { DCE } & \text { Diol-modified 2-nitro-4-propynylpyrrole } \\ \text { ELASA } & \text { DNA capture element } \\ \text { ECDC } & \text { Enzyme-linked aptamer sedimentation assay } \\ & \text { European Centre for Disease Prevention } \\ \text { FITC } & \text { and Control } \\ \text { FRET } & \text { Fluorescein isothiocyannate } \\ \text { FACS } & \text { Fluorescence resonance energy transfer } \\ \text { HTS } & \text { Fluorescence-activated cell sorting } \\ \text { Ds } & \text { High-throughpuT-SELEX } \\ \text { MREs } & \text { Hydrophobic base 7-(2-thienyl) imidazo[4, } \\ \text { NECEEM } & \text { 5-b]pyridine } \\ \text { OMPs } & \text { Molecular recognition elements } \\ \text { QDD } & \text { Outer memilibrium capillary electrophoresis } \\ & \text { Quantum dot }\end{array}$




$\begin{array}{ll}\text { SELEXp } & \begin{array}{l}\text { Systematic evolution of ligands by } \\ \text { exponential enrichment }\end{array} \\ \text { SEA } & \text { Staphylococcus aureus enterotoxin A } \\ \text { SEB } & \text { Staphylococcus aureus enterotoxin B } \\ \text { SERS } & \text { Surface-enhanced Raman spectroscopy } \\ \text { TECS-SELEX } & \text { Target expressed on cell surface-SELEX } \\ \text { UCNPs } & \text { Up conversion nanoparticles } \\ \text { ROX } & \text { X-rhodamine }\end{array}$

\section{Introduction}

Foodborne pathogens are life threating to a community in general and particularly to people susceptible to disease. Common causative agents include bacteria, viruses, parasites, and other microbes. Pathogenic microorganisms easily find their way into a food and ultimately into consumer, especially in an unhygienic environment in a food chain. Poor conditions in a food production chain are a major source of unsafe food, often with a considerable load of pathogens which could cause severe illness. Recent US Centers for Disease Control and Prevention reports show that 2.2 million people die every year, of which 1.9 million are children due to pathogenic bacteria: specifically, Bacillus sp. (cereus, thuringiensis, and anthracis), Campylobacter sp., Escherichia sp., Listeria sp., Salmonella sp., and Staphylococcus sp. are associated with foodborne and waterborne disease outbreaks (Control CfD 2013; Sett 2012). Therefore, to ensure food safety for consumers, a strict and reliable quality control and assurance approach must be implemented. To combat the ever-increasing succession of unsafe food norms, several analysis-based food safety measures have been developed such as immunological methods (conventional ELISA), immunomagnetic electrochemiluminescence assay, time-resolved fluorescence assay, rolling circle amplification, and strand displacement amplification. Despite all these innovations, many challenges exist in developing sensitive and reliable analytical methods with fast detection of specific food hazard(s) (AmayaGonzalez et al. 2013; Hayat et al. 2013; Litao Yang 2007; Velusamy et al. 2010). The ineffectiveness of non-nucleic acid based techniques is associated with complicated handling procedures, strict laboratory protocols, high cost, and significant susceptibility to change in conditions (Tombelli et al. 2007). Aptamers and their biosensor-derived techniques rapidly detect food contaminants at extremely low levels yielding a promising pathogen detection approach (McKeague and Derosa 2012; McKeague et al. 2014; Xu et al. 2011). Aptamer-based biosensors play a pivotal role to lessen this apprehension, since they are ideal candidates to improve testing. Use of aptamers in foodborne pathogen detection was first reported in 1990 (Tuerk 1990a), since then numerous biosensors have been designed for different targets from agri-food, environmental, pharmaceutical, and therapeutical origin (Beier et al. 2014a; Scognamiglio et al. 2014; Thiel and Giangrande 2009). However, still few putative techniques in detection of parasites (Giardia lamblia, Taenia saginata, Taenia solium, Entamoeba histolytica, Cyclospora Cayetanensis, Pseudo terranova spp., Sarcocystissui hominis), fungi (yeasts, molds), and viruses (Hepatitis A, Avian influenza, Rotovirus) and some bacteria (only M-type 11 Streptococcus pyogenes) are implemented.

In vitro selection and production attempts of bare and conjugated aptamer biosensors range from microbial detection to metabolic pathway study towards therapeutic usage (Bini et al. 2011). They are developed using systematic evolution of ligands by exponential enrichment (SELEX) protocol and bind to the target by inducing the duplexes dissociation and single strand DNA/RNA folding in a unique 3-D structure. This is achieved in two different ways namely specific ligands and/or through Watson-Crick complementary strand binding (Marty and Hayat 2014). They possess high affinity and specificity binding to numerous target molecules namely inorganic ions $\left(\mathrm{Zn}^{2+}\right)$, small molecules (biotin), organic dyes (malachite green), nucleotides (ATP), amino acids (citrulline, arginine), neutral disaccharides aminoglycoside antibiotics, proteins, large glycoproteins (CD4), viruses, anthrax spores (Zhijun Guoa 2011), cells (Drabovich 2009), toxins, drugs, lowmolecular-weight ligands (Subramanian Viswanathan 2008), environmental pollutants, and disease biomarkers (Mei 2013).

Cell-SELEX provides flexibility in the detection of various cell types (bacteria, viruses, cancer cells) and is now used in the identification of the unknown cells' surface biomarkers (Kim et al. 2013c). Recently, modified SELEX protocols based on traditional SELEX method have significantly improved to advance the application of aptamer technology in various fields (Xu et al. 2011). SELEX process is modified to obtain aptamers with specific features towards definite uses (Stoltenburg et al. 2007). Chemical modifications of aptamers depend on their applications, primarily to increase their stability against biological fluids, introducing reporter molecules and/or functional groups and immobilization (Stoltenburg et al. 2005b). The immobilization of modified aptamers on the surface of biosensors through various fixation methods such as direct attachment (a biosensor's gold electrodes bind to thiol-modified aptamers), covalent binding (amino groupmodified aptamers react covalently with different chemical groups (amino, carboxyl, hydroxyl, etc.), and biocoatings (avidin-coated biosensor bind with high specificity and affinity to biotin-labeled aptamers) exert impacts on the properties of biosensors which, in turn, enhance the performance of aptasensors (Zhou et al. 2011). These oligonucleotides are able to form a specific hairpin loop allowing them to recognize a variety of targets even for closely related pathogenic bacteria (Table 1). Though all improvements, aptamer technology still needs refinements to obtain aptamers with target specificity and strong binding properties in different environmental 


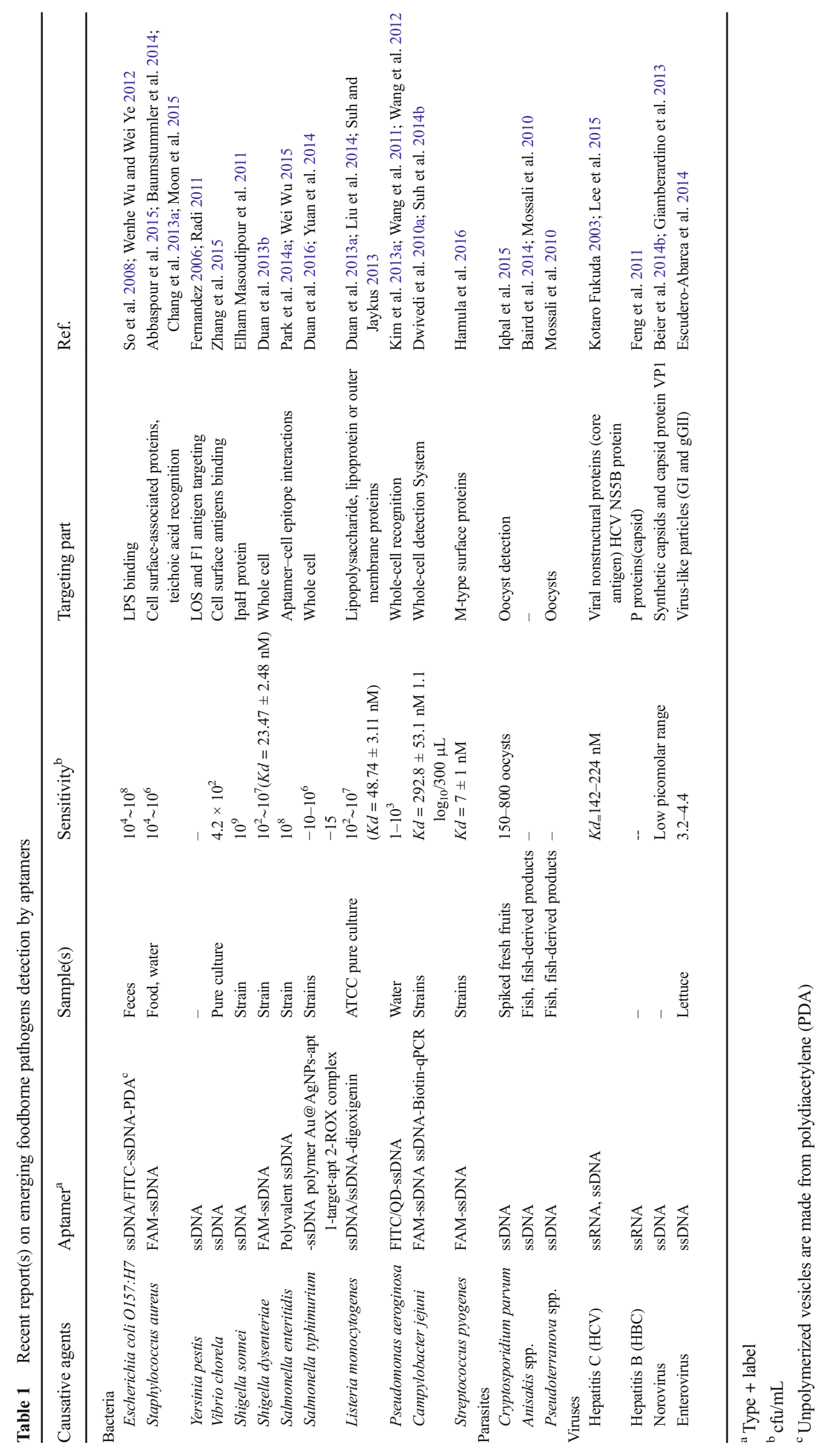


conditions like $\mathrm{pH}$ variation, nuclease presence, salt concentrations, and temperature (Tombelli et al. 2007; Tibor Hianik 2007). Hence, this review aims to cover comprehensively current implemented bare and conjugated aptamer-based multiplex techniques in detection of food pathogens. The putative aptamers will be discussed in the context of their selection through modified whole-cell SELEX, proceeding to the mode of action and culminating with their advantages towards more accurate and reliable bioanalysis.

\section{General Principle and Modified SELEX for Foodborne Pathogens}

Aptamers against specific targets are selected through a process termed as SELEX (Tuerk 1990b) which is based on chemically synthesized oligonucleotide forming a combinatorial library. The latter consists of multitude of single-stranded DNA (ssDNA) or RNA fragments with different sequences $\left(\sim 10^{14}-10^{16}\right)$ (Marty and Hayat 2014). This selection process for emerging pathogenic microorganisms has two critical steps: (1) targets screening and (2) separation of the binding sequences. Briefly, the selected aptamers are initially incubated with the target(s) of interest (i.e., pathogens) followed by separating the high-affinity aptamers from that of unbounded target(s). Next, the eluted aptamers are amplified using polymerase chain reaction (PCR) to get an enriched pool for more selection rounds. These aptamers are cloned, sequenced, characterized, and may be manipulated to achieve aptamers with desired characteristics (Fig. 1) (McKeague and Giamberardino 2011; McKeague and Giamberardino 2011; Wang et al. 2012).

The ultimate goal of modifications is to select aptamers with specific properties such as efficiency, rapidity, and less labor. Based on aptamer properties and screening methods, the SELEX process has been improved to get high-affinity and selectivity aptamers via improving selection, amplification, and pool enrichment monitoring (Kim and Gu 2014). Other changes include target immobilization and nucleic acid library expension (McKeague and Derosa 2012). For oligonucleotide stability and resistance against nuclease enhancement, several SELEX protocols have been developed such as genomic SELEX or cDNA-SELEX (Zimmermann et al. 2010), covalent SELEX (Kopylov and Spiridonova 2000; Spiridonova 2014; Spiridonova et al. 2014), deconvolution SELEX or subtractive SELEX (Torres-Chavolla and Alocilja 2009), photo SELEX (Cho et al. 2004), and multistage SELEX (modified chimeric SELEX) (Wu and Curran 1999) for rationalization of starting pool. Counter SELEX or negative SELEX protocol in aptamer is for selectivity enhancement (Xi et al. 2014). For target applicability, expression cassette (Martell et al. 2002), TECS-SELEX (Ohuchi et al. 2006), whole-bacteria SELEX (Torres-Chavolla and Alocilja 2009), mirror-image SELEX
(Klussmann et al. 1996), blended SELEX (Kulbachinskiy 2007), toggle SELEX target-switching (Hamula et al. 2006), whole-cell SELEX (Park et al. 2014b), complex target SELEX (Chen 2007) are more promising. Current emerged techniques such as HTS or automated SELEX (Huenniger et al. 2014; Lu et al. 2014), Non- or NECEEM-SELEX (Ashley et al. 2012; Yun et al. 2014), CE-SELEX (Kasahara et al. 2013), FluMag-SELEX (Stoltenburg et al. 2005a), microfluidic SELEX (Lin et al. 2014), and in silico SELEX (Nonaka et al. 2013; Savory et al. 2013) have improved efficiency of designed aptamers in both binding affinity and high throughput in tertiary structure prediction, thermodynamic, and aptamer-target model (Das et al. 2010). Despite all these enumerated SELEX techniques, some whole-cell-selected aptamer candidates would have high affinity but poor specificity (Hamula et al. 2008). Thus, in most current used techniques for pathogens detection, accurate counter selection and FACS sorting (FACS-SELEX) steps are crucial for effective aptamer candidates (Fig. 2) where bound sequences are perfectly separated from unbound ones. Moon and others reported that the use of cell sorting followed by FAM-labeling of aptamer candidates improved the affinity up to a $K d$ of $3.49 \pm 1.43 \mathrm{nM}$ (Moon et al. 2014).

SELEX protocol modification has been acquired also in optimizing PCR amplification towards precise number of rounds franking primer sequences to the high-affinity sequences of oligonucleotides. In this novel in vitro selection, fixing primer sequences allows to restrain a double-stranded structure of oligonucleotides. It allows primerless selection to prevent the primer binding sequences to incorporate into the target oligonucleotide-binding motif (Florian Jarosch 2006). Additionally, the use of unnatural bases (library modification) using expanded genetic alphabet of oligonucleotides contributed to a $>100$-fold affinity DNA aptamers as compared to the natural ones. Kimoto and colleagues have designed a DNA aptamer with four natural nucleotides (dNTPs) and unnatural nucleotides (dDsTPs, $\mathrm{dPx}$, and $\mathrm{dPaTP}$ ) recognizing the human proteins such as signal protein vascular endothelial cell growth factor-165 (VEGF-165) and interleukins (interferon- $\gamma($ IFN- $\gamma$ ) with binding affinity of $K d$ values of $0.65 \mathrm{pM}$ and $0.038 \mathrm{nM}$, respectively) (Kimoto et al. 2013). In addition, the use of IsoG, IsoC, and other unnatural base pairs combined to the natural ones functions as third base pair. These modifications are prominent to high efficiency and selectivity in new modified SELEX process through hydrogen bonding principle and their inotropic properties towards aptamers (Fig. 2); however, to date, few reports have been applied to affinity selection methods. Furthermore, polynucleotide library with modified polynucleotides such as $2^{\prime}$-amino pyrimidines, 2'-fluoro pyrimidines, 2 '- $O$-methyl nucleotides, boranophosphateinternucleotide linkages, $5^{\prime}$-modified pyrimidines, 4'-thio pyrimidines, phosphorothioate inter-nucleotide linkages providing high stable and affinity, nuclease resistant, 
Fig. 1 Schematic illustration of SELEX process with slight modifications for high affinity aptamer generation

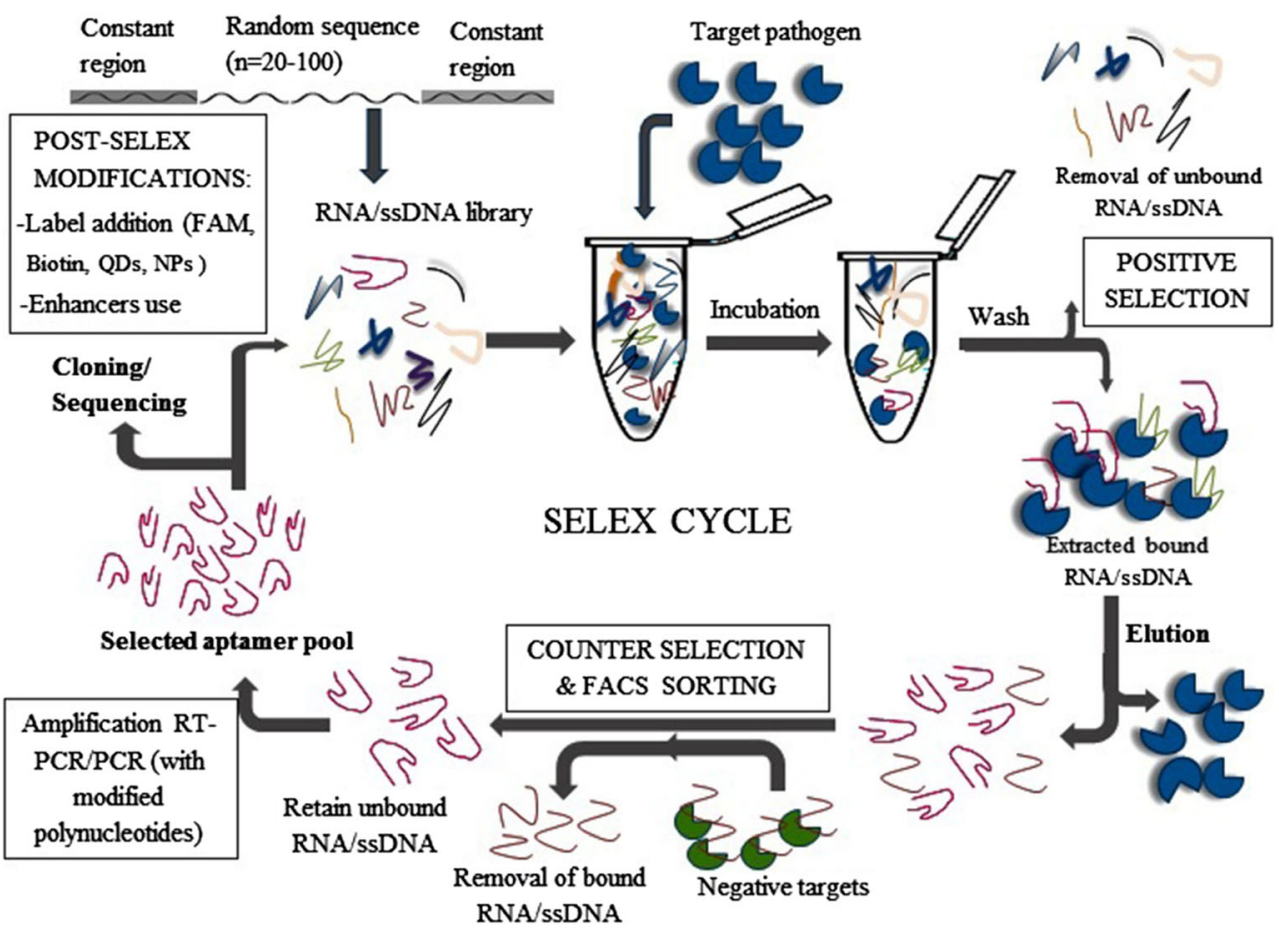

Food Pathogen Detection with Aptamers

and most importantly SELEX-compatible and cheap synthesis aptamers (Keefe and Cload 2008) showing their use in both therapeutic and diagnosis of diseases and detection of tiniest emerging foodborne pathogens.
Foodborne illnesses and outbreaks are commonly caused by bacteria. Typically, symptoms of infection do not appear until
Fig. 2 Illustration of improved process of FACS-SELEX process for high affinity aptamers selection: Classic method: contains ten rounds of SELEX and only one FACS sorting. This procedure gives aptamers with adequate binding affinity (Aptamer A). More current procedure of FACS-SELEX provides aptamers with high binding affinity to its targets with less SELEX rounds (Aptamer B). In this process, the oligonucleotide library is fluorescently labeled and then preincubated with a mixture of different kinds of targets. Aptamers can be separated by flow cytometer depending on affinity. The aptamers bound only to the cells of interest are then eluted, purified, and amplified

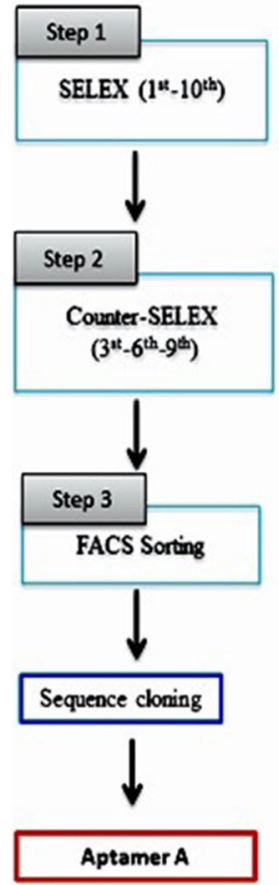

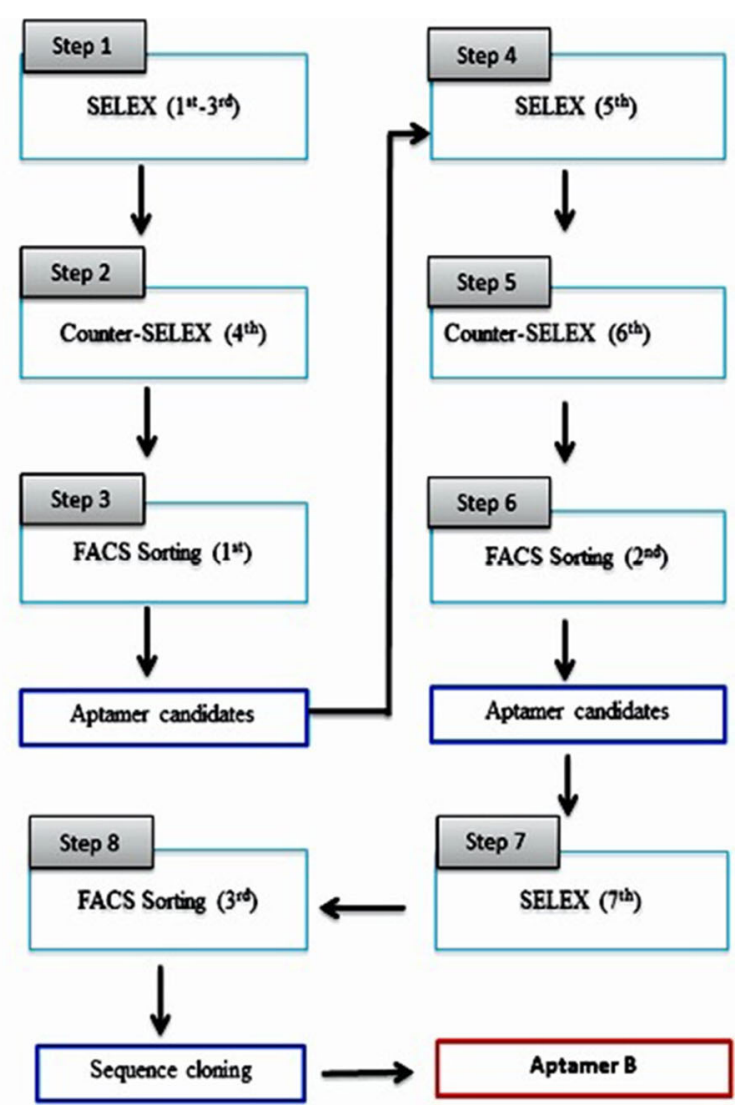


$\sim 12-72 \mathrm{~h}$ after food ingestion. Thus, it is a need of hour to detect pathogens timely, rapidly at very low levels in complex food matrices to lessen the risk of illness and to avoid product recalling. To overcome these challenges, a number of aptamers and nanomaterial-labeled aptamers in conjunction with electrochemical transduction output with high potential for bacteria detection have been developed (Marty and Hayat 2014; McKeague et al. 2011). Nanoparticles such as silver, gold, and quantum dots are utilized as novel tools as compared to immunoassay-based and chromatography-based methods, because they provide fast and reliable detection approach for pathogens that pose serious concerns to humans. The underneath described putative aptamers could be considered as potential approaches for detection of common food pathogens namely Salmonella sp., Staphylococcus aureus Bacillus sp., Campylobacter sp., Escherichia coli, Shigella sp., Listeria monocytogenes, and Streptococcus pyogenes.

\section{Salmonella Species}

They are the most common foodborne causative agents of parathyroid fever, typhoid fever, and salmonellosis with multidrug resistant strains. The classic microbiological detection of Salmonella genera requires standard steps of cultivation such as preenrichment, selective enrichment, and selective differential media plating which are tedious, expensive, complex operations and require long time of incubation. DNA aptamers has demonstrated binding specificity to most of the genera. Dwivedi and others developed selected an aptamer recognizing S. typhimurium through magnetic capturing. In this study, primers were prelabeled and obtained DNA aptamer pool has been sorted using FACS followed by biotinylation. It displayed less cross-reactivity to other foodborne pathogens and possessed good $K d$ of $1.73 \pm 0.54 \mu \mathrm{M}$ detected in low sample of $290 \mu \mathrm{L}$ containing $10^{2}-10^{3} \mathrm{cfu} / \mathrm{mL}$ (Dwivedi et al. 2013). The use of FACS shows a remarkable alternative in production of high affinity and pure aptamers recognizing specifically cell membranes compartments (Jay 2013). In addition, an electrochemical biosensor was developed using a Salmonella-specific recognition aptamer biosensor. It is made with a glassy carbon electrode@ graphene oxide and aptamer-functionalized gold nanoparticles (AuNPs). This aptamer ssDNA sequence could be linked to electrode via thiol (-SH) groups and AuNPs using three-electrode systems where Salmonella is incubated to generate current between electrodes by decreasing the electrolyte that resulted in high resistance. The selected aptamer has high specificity and selectivity with detection range of $2.4-2.4 \times 10^{3} \mathrm{cfu} / \mathrm{mL}$ that was achieved and LOD of $3 \mathrm{cfu} / \mathrm{mL}$ (Ma et al. 2014) Fig. $3 \mathrm{~b}$.

For S. typhimurium, the RNA aptamer-based ligands were specifically identified through SELEX. The isolated and characterized RNase-resistant RNA aptamer was targeting outermembrane proteins $(\mathrm{OmpC})$ with high specificity and affinity
$(K d=20 \mathrm{nM})$. The selected aptamer binds only to $S$. typhimurium, and none of other related bacteria used in counter selection bounds to it (Han and Lee 2013). However, resilient efforts were made in whole-cell SELEX modification to increase the success rate. Four important steps summarize this modification: (1) incubating the ssDNA library with live Salmonella sp. at ambient temperature for aptamers binding, (2) separating the bound and unbound ssDNA from target in centrifugation process, (3) amplification of the bounded ssDNA (in this process, ssDNA is concentrated by PCR-Ultracel), and (4) finally, ssDNAs are sorted, cloned, sequenced, and then individually characterized according to their binding affinity for Salmonella cells using flow cytometry. Through abovementioned process, a potential ligand aptamer (5'-ACGGGCGTGGGGGCAATGCT GCTTGTAG CCTTCCCCTGTGCGCG-3') has been selected for capturing S. typhimurium (Moon et al. 2013). Other aptamer candidates such as 5'-TATGGCGGCGTCAC CCGACGGGACTTGACATTATGACAG-3' and GAGGAAAGTC TATAGCAGAGGAGATGTGTG AACCGAGTAA have also been selected after the seventh round of SELEX and exhibited low LOD of 10-40 cfu/mL. These aptamers are DNase resistant which enhance specificity towards outer membrane proteins (OMPs) and high affinity detection when using spectrometry (Raghavendra Joshi 2009). Another selection of S. typhimurium with highaffinity ssDNA aptamer was designed based on bacteriumbased SELEX. The sequence (5'-FAM-ATAGGAGT CACGACGACCAGAAAGTAATGCCCGGTAGTTATTCA AAGA TGAGTAGGAAAAGATATGTGCGTCTACCTCTT GACTAAT-3') showed a high affinity for $S$. typhimurium $(K d=6.33 \pm 0.58 \mathrm{nM})$. With this aptamer, the detection range of $50-10^{6} \mathrm{cf} i \mathrm{~mL}$ and LOD of $5 \mathrm{cfu} / \mathrm{mL}$ were obtained (Duan et al. 2013c). These approaches could be employed to develop an easy, rapid, and sensitive methodology for other closely related pathogen detection in food(s) as only aptamerAuNPs based colorimetric method can detect $10^{6} \mathrm{cfu} / \mathrm{mL}$ (Moon et al. 2014).

Recently, aptamer-combined AuNPs is ever-increasing in the most successful strategy in pathogen detection. Yuan and others used biotinylated aptamer (1)/bacterial/aptamer (2)AuNPs sandwich system with 5'-biotin-C6-TATGGCGG CGTCACCCGACGGGGACTTGACATTAT GACAG-3' and 5'-SH-TATGGCGGCGTCA CCCGACGGGGACTT GACATTATGCAG-3' for Vibrio parahaemolyticus and S. typhimurium aptamer-AuNPs, respectively. The aptamers were immobilized on the well's surface of the microtiter plate via biotin-streptavidin binding accompanied by silver enhancement for binding specificity, sensitivity, and stability. The optimal addition of silver enhancer solution provides visual differentiation between $S$. typhimurium and other foodborne bacteria through signal intensity. With this method of gold-labeled silver staining, the LOD of $S$. typhimurium 


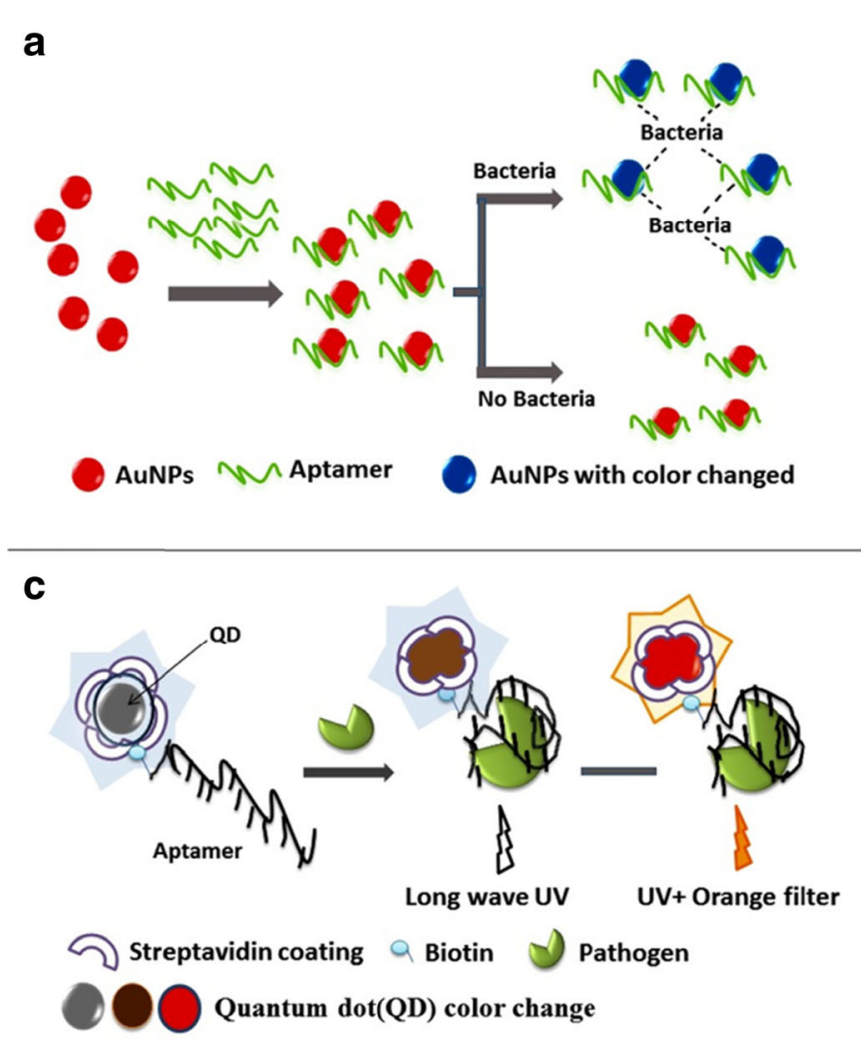

Fig. 3 Aptamer enhancers: Aptamer-functionalized gold nanoparticle (AuNP). AuNPs possess a strong surface plasmon resonance band, which has strong distance-dependent properties. When AuNPs bind to targeted sites and come into close proximity with other AuNPs, they change the refractive index of the surrounding medium, resulting in a color change from red to purple. a Graphene oxide-SELEX: The ssDNA library is preincubated with AuNPs followed by adsoption on GO via to $\pi-\pi$ bonding. b. The DNA capture element (DCE) system quenching and dequenching. This process consists of fluorophore (e.g., QDs, FAM,)-labeled starting ssDNA library through covalent linkage at the $3^{\prime}$ end and a bead covalently linked to the $5^{\prime}$ end, and the

reached $7 \mathrm{cfu} / \mathrm{mL}$ (Yuan et al. 2014) which depicts the prospective utilization of combinatorial techniques in improving the microbial visual detection (Fig. 3d).

Few years back, we used aptasensors and dual fluorescence from green QDs and red QDs nanoparticles as donors and amorphous carbon nanotubes as acceptors could give the LOD of 25 and $35 \mathrm{cfu} / \mathrm{mL}$ in food sample for Vibrio parahaemolyticus and S. typhimurium, respectively (Duan et al. 2013d). Interestingly, this method provided improved simultaneous and visual detection of pathogens based on QDs fluorescence which is linearly proportional to the target concentration. Furthermore, a high affinity aptamer (5'-ATGGACGAATATCGTCTCCCAGTGAATT CAGTCGGACAGCG-3') has been screened using whole-cell SELEX conjugated carbon nanomaterials to detect the $S$. paratyphi A and achieved $K d=47 \pm 3$ nM. Additionally, a SWCNTs@ DNAzyme- aptamer combination was designed for this b

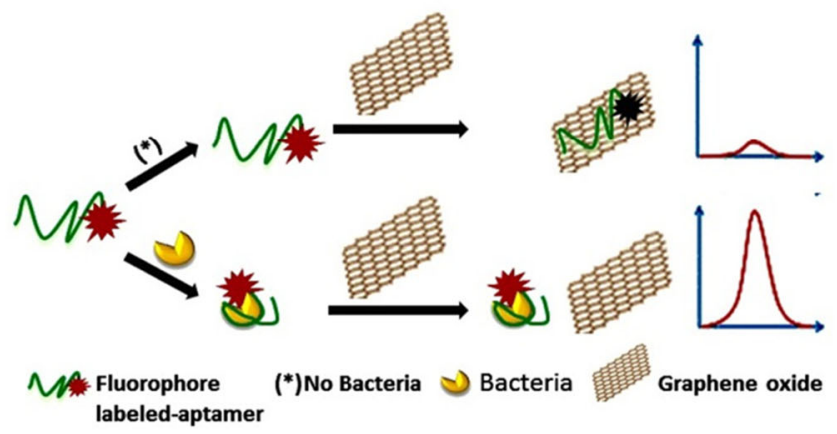

d

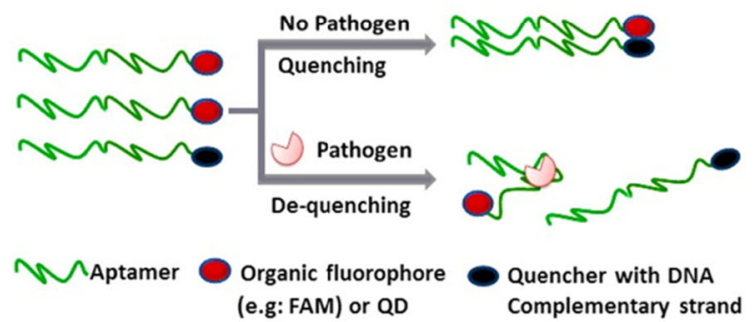

complementary strand aptamer has a quencher covalently linked to the 5 ' end. The two strands of DNA are annealed together, and the quencher quenches the fluorescence of the fluorophore. The presence of targets triggers the DCE system fluctuation resulting in the double strands denaturation which gives fluorescencer. $\mathbf{c}$ Illustration of capture aptamer and UV light requirement to immobilize the capture aptamer. Colloidal gold or quantum dot is used as reporter conjugate. d The aptamer multiplex system may involve digoxigenin-5' reporter aptamer-3'biotin-streptavidin colloidal gold or Q-dot conjugates, amino-capture aptamers immobilized with UV light for colorimetric observation. The intensity of the dots increases proportionally with targets

pathogen and this complex has self-aggregation in the presence of specific target. A linear range of $10^{3}-10^{7} \mathrm{cfu} / \mathrm{mL}$ was attained with a LOD of $10^{3} \mathrm{cfu} / \mathrm{mL}$ (Ming Yang 2013). More currently, a remarkable combinatorial technique of $S$. typhimurium detection has been published. Here, A Surface-enhanced Raman spectroscopy (SERS) substrate bearing Au@AgNPs combined with 5'-SH-aptamer 1 for target cells capture followed by aptamer 2 modification using X-rhodamine (ROX) (recognition element and SERS reporter). S. typhimurium specifically bind with the aptamers to form Au@AgNPsaptamer1-target-aptamer2-ROX sandwich-like complexes. This tremendous technique results a rapid and high sensitive detection with a linear range of $15-1.5 \times 10^{6} \mathrm{cfu} / \mathrm{mL}$ with a LOD $15 \mathrm{cfu} / \mathrm{mL}$ (Duan et al. 2016). Though many techniques have been discussed, this technique promises potential use in foodborne pathogens detection in terms of LOD and feasibility. 


\section{Staphylococcus aureus}

It is a pathogen commonly found in food. It secretes a mixture of enterotoxins known as staphylococcal enterotoxins A and B (SEA and SEB). (Bruno et al. 2010; Bruno JG 2002; Tombelli $S$ 2007). For these toxins, aptamer targeting SEB1 has been selected for SEB (DeGrasse 2012b). Though its high affinity and selectivity together with other several ssDNA aptamers to SEB were described, their aptamer sequences are not implemented, limiting their utilization. For S. aureus SEA, a method based on primarily antibody dependent was replaced by aptamers that bind to target with high affinity and selectivity. Those aptamers were selected and generated in vitro by a 12round selection process based on magnetic separation $(K d=48.57 \pm 6.52 \mathrm{nM})$. This aptamer shows more reliable results consistent with previously reported $S$. aureus SEA detection having a LOD of $8.7 \times 10^{-3} \mu \mathrm{g} / \mathrm{mL}$ (Huang et al. 2014) with low cost and high affinity compared to its antibody-based counterpart which is challenging and laborious.

For whole-cell-based SELEX, $10^{7} \mathrm{~S}$. aureus have been incubated for aptamer selection followed by isolation of bound aptamers. In the counter-selection process, aptamers with specific binding were incubated with structurally related negative targets $\left(10^{8}\right.$ S. epidermidis $)$ and highly specific aptamers were amplified and purified. The selected ssDNA was again incubated with new $S$. aureus to start next SELEX round(s) and after eight rounds cloned and sequenced. Likewise, a panel of ssDNA aptamer specific to S.aureus was obtained by a whole bacterium-based SELEX and applied to probing S. aureus. Here, 11 sequences from different families were selected for further characterization by confocal imaging and flow cytometry. The $K d$ values obtained for a single candidate aptamer were in the nanomolar range and showed a high specificity (Cao et al. 2009). Recently, combinatorial assays for simultaneous detection of three pathogenic bacteria was developed using multicolor up conversion nanoparticles (UCNPs) as luminescence labels coupled with aptamers as the molecular recognition elements (Wu et al. 2014). Other simple and fast method based on a polydimethylsiloxane (PDMS)/paper/glass hybrid microfluidic system integrated with aptamerfunctionalized graphene oxide nanobiosensors for simple, one-step, multiplexed pathogen detection has been developed. This method has been simultaneously used in detection of two infectious pathogens S. aureus and S.enterica (Zuo P 2013 ). Chang et al. performed two ssDNA aptamers with high affinities and specific against $S$. aureus $(K d=35$ and $129 \mathrm{nM})$. This $K d$ was improved to 3.03 and $9.9 \mathrm{nM}$ which demonstrated the detection of single $S$. aureus cell in $1.5 \mathrm{~h}$ and promised the constructed aptamer to be used in food safety for $S$. aureus detection (Chang et al. 2013b). Recently, chemically modified aptamer-functionalized grapheme oxide combinatorial technique has been developed able to detect a single colonyforming units per milliliter. In this technique, graphene works as a transducer layer of aptasensor while the aptamer is a sensing body. The modified graphene showed less noise compared to non-modified in detection of challenging strains like S. aureus (Hernández et al. 2014). This study demonstrated a high sensitivity of combination than either bare-used aptamers or nanomaterials in recognizing $S$. aureus. This technique promises potential use in foodborne pathogen detection. Though its high affinity and selectivity together with other several ssDNA aptamers to SEB were described, however, their aptamer sequences are not implemented in lieu or as alternative of antibodies, limiting their utilization (DeGrasse 2012a).

\section{Bacillus Species}

Bacillus anthracis is a rod-shaped, Gram-positive bacteria able to form endospores. It causes disease to both human and livestock owing to its immune system escaping mechanism and causes high fatality rate derived from its high load in food such as hot chocolate, rice, mashed potatoes, and turkey and meat loafs (Drobniewski 1993; King et al. 2007). Etiologically, it is known as major cause of anthrax in livestock and toxicity in human acquired from its membrane surface protein capsule namely poly-D-gamma-glutamic acid and lethal factor endopeptidase that hydrolyze mitogen-activated protein kinase kinases (virulence part). Recent novel strategies are able to differentiate between the Bacillus strains although some setbacks occur in detection of $B$. anthracis especially phenotypic and genotypic resemblance within bacillus genera thus high possibility of getting the false results. For example, B.thuringiensis and B.cereus are closely related with $B$. anthracis with only two dissimilarities: (1) two virulence plasmids in $B$. anthracis and insecticidal toxins coding plasmids in B. thuringiensis (Warda et al. 2016). Gram-positive bacteria $B$. cereus is responsible for causing severe nausea, vomiting, diarrhea, and other similar foodborne illness that has the threshold for onset the disease(s) is $>10^{6}$ B. cereus $/ \mathrm{g}$ in food produce (Helgason E 2000), and yet, no putative aptamer-conjugated essay was reported. As B. thuringiensis is also injurious to human, a DNA aptamer 5'-CAT CCGTCACACCTGCTCTGGCCACTAACATGGGG ACCAGGTGGTGTTGGCTCCCGTATC-3' was specific for B. thuringiensis whereby combination of 60 base aptamer to fluorescent zinc sulfide-capped cadmium selenide quantum dots (QD) detect B. thuringiensis (B. cereus closely related bacteria). During this testing, several controls with nonfunctionalized QDs and without spores were verified and validated to measure QDs specificity to the spores and the fluorescence attained the LOD of $10^{3}-10^{4} \mathrm{cfu} / \mathrm{mL}$ (Ikanovic et al. 2007; Torres-Chavolla and Alocilja 2009). For specificity purposes, the detection of $B$. globigii spores (B. subtilis vs. $B$. niger) can differentiate $B$. thuringiensis from $B$. globigii at concentrations above $105 \mathrm{cfu} / \mathrm{mL}$ (Lim et al. 2010) (Fig. 3b). Additionally, the use of Raman spectroscopy 
combined to the single-walled carbon nanotube (SWCNT) generates high affinity oligonucleotides for $B$. anthracis detection. A complementary DNA to the target DNA is added to DNA-SWCNT complex resulting hybridization (Bansal et al. 2013).

To date, SELEX is the most often used process in aptamer selection for various purposes including food safety. However, during the selection process, it requires high amounts of target molecules. Therefore, as a possible alternative, another sensing system called DNA capture element (DCE) is used to detect scarce pathogens (Tuerk 1990b). B. anthracis, Shiga toxin, botulinum neurotoxin (BoNT), and Francisella tularensis DCE systems have been developed from their aptamers (Mathew et al. 2015; Tuerk 1990b). In DCE approach, the target interacts with dsDNA and magnetic separation technology followed by its denaturation (quenching and dequenching system) resulting fluorescence signals (Fig. 3c) (Fan et al. 2008). The resulted target-bound ssDNA complex can be separated later by random ssDNA magnetic beads. The use magnetic beads requires very small amount of target during ssDNA/target separation and helps in signal amplification. The bacillus spores were used as targets of DNA aptamer during screening, and 79 DNA fragment sequences from 13 different classes of DNA aptamers were obtained by 18 cycles (Wang et al. 2012). A DNA aptamer (5'CATCCGTCACACCTGCTCTGGCCACTA-3') obtained against spores of B.anthracis strain has paved the way to develop more sophisticated aptamer-magnetic beadelectrochemiluminescence (AM-ECL) sandwich technique with high sensitivity of detecting $<10 \mathrm{~B}$. anthracis spores (Xu et al. 2011). The binding of quantum dot (QD)-labeled aptamer to B. cereus, B. anthracis spores, could be applied to target similar pathogens (Yang et al. 2013).

\section{Campylobacter jejuni}

Campylobacter jejuni is a common food poisoning bacterium and mainly found in raw meat, raw milk, and crosscontaminated foods. When ingested with contaminated food, it colonizes the intestine wall and produces enterotoxins. Dwivedi and others performed cell-SELEX on live C. jejuni by applying combinatorial library of FAM-labeled ssDNA on whole-cell SELEX method. Here, ssDNA molecular recognition elements (MREs) are used followed by FACS sorting targeting $C$. jejuni A9a. These aptamers showed high affinity and specificity against the target with relative high dissociation constant of $292.8 \pm 53.1 \mathrm{nM}$ (Jaykus 2010; Dwivedi et al. 2010b). Furthermore, Stratis-Cullum and others performed a CE-SELEX to evaluate the aptamer specific for dead C. jejuni with qualitative capillary electrophoresis immunoassay and the obtained LOD was $6.3 \times 10^{6}$ cells $/ \mathrm{mL}$ (Stratis-Cullum et al. 2009). Aptamer-linked QDs have been developed and used in a sandwich assay in conjugation with magnetic beads for the detection of $C$. jejuni at levels of between 2.5 and 10-50 cfu/ $\mathrm{mL}$ in buffer and food matrices, respectively (Bruno et al. 2009). However, currently, it was proved that biotinylated magnetic bead-based aptamers followed by qPCR detection of $C$. jejuni in sample volume range of $300 \mu \mathrm{L}$ to $10 \mathrm{~mL}$. This combination targets the glyA gene and is species specific with clear exclusion of closely related genera (Suh et al. 2014b). The qPCR complemented with biotinylation properties such as fast on rate, specificity, affinity, and nucleic acid stabilization. The principle behind consists of aptamer conjugation to its target with donor and acceptor microbeads. After interaction, there is fluorescent signal production which could be read by fluorescence reader. This automated biotinylated magnetic bead qPCR-based aptamers can simultaneously detect targets with high affinity and in a short time.

\section{Escherichia coli}

Escherichia coli have enterotoxigenic effects and potentially contaminate food and water (Castro-Rosas et al. 2012). Detection of $E$. coli $\mathrm{O} 157: \mathrm{H} 7$ is of high priority in food surveillance as this Gram-negative bacteria cause infection which may lead to hemorrhagic diarrhea and kidney failure (Bieke Van Dorsta 2010; McKeague and Giamberardino 2011). Sensitive methods are of great importance as the infectious concentration can be as low as $10-100 \mathrm{cfu} / \mathrm{mL}$. Several DNA and RNA aptamer-based platforms have been developed for several strains of foodborne E.coli. One example is an aptamer-modified SWCNT in both field-effect transistors and label-free potentiometric measurements to provide rapid and reusable biosensors. For effective potentiometric aptamerbased biosensor, a FRET-based assay using a DNA aptamer for nonpathogenic $E$. coli CECT 675 strain is used as a model organism substitute for pathogenic E. coli O157:H7. The SWCNT works as ion-electron transducers, and aptamers are covalently immobilized on it as a biorecognition elements. Aptamers interact with target(s) with subsequent electrical potential changes that enables quick identification and detection of the target. As a result, $10^{4} \mathrm{cfu} / \mathrm{mL}$ can be detected selectively and this biosensor can be built and regenerated easily with a low LOD in complex samples (Zelada-Guillén et al. 2010). Furthermore, aptamer-functionalized SWCNT fieldeffect transistors have also been reported for the detection of E. coli DH5 $\alpha$ strain (So et al. 2008). However for endotoxins, producing $E$. coli strains, only E. coli $\mathrm{O} 111: \mathrm{B} 4$ endotoxin is reported. Here E. coli cells or lipopoplysaccharide (LPS) are used as target for selecting specific aptamer and showed high affinity and selectivity when analyzed by a colorimetric enzyme-based technique (Bruno et al. 2008).

Other nanomaterials in conjunction with aptamer-based biosensors for $E$. coli detection were developed. An example is a $\mathrm{Fe}_{2} \mathrm{O}_{3}-\mathrm{AuNP}$ s electrochemical DNA biosensor. This DNA biosensor forms a sandwich complex made of 
recognition element on $\mathrm{Fe}_{2} \mathrm{O}_{3} @$ AuNPS, reporter@HRP enzyme, and the target. After $E$. coli capture, the induction of magnetic field activates magnetic separation of complexes leading to HRP catalysis resulting in detectable signals. The LOD of $5 \mathrm{cfu} / \mathrm{mL}$ was achieved without requiring PCR amplification of target DNA (Li et al. 2011), though it required long-time incubation period (Fig. 3a). This assay is reliable; however, its detection sensitivity is of concern in terms of working time. Therefore, a DNA aptamer-quantum dot lateral flow test strip can improve the detection time and provide colorimetric results for more common foodborne pathogens. At the presence of targets, the high-affinity selected aptamers stabilize nanoparticles and the latter act as signal transducer elements via their aggregation leading to pinkish visible color change from red (Bruno 2014).

Currently, Kim and others detected E. coli strains that used fluorescence-tagged aptamer cocktails and found this can boost signals than single aptamers. The use of three various aptamer cocktails, each labeled with FAM, is able to recognize one particular bacterium and target the outer membrane compartments. Compared to single aptamers, the cocktail enhances sensitivity and fluorescence signal simultaneously with cumulative influence. This method is attractive because it can reduce the LOD from 6778 to $3.7 \times 10^{2} \mathrm{cfu} / \mathrm{mL}$ of single aptamer and multiple ones, respectively (Kim et al. 2014). However, due to outer cell surface complexity, molecular level understanding of how these aptamers bind on E. coli strains is still unknown. Using, the same aptamers could bind to cell surface components competitively followed by fluorescence emission; therefore, two or more different aptamers could be assumed to bind non-competitively (Kim et al. 2013c).

\section{Shigella Species}

Shigella dysenteriae is a Gram-positive, facultative intracellular and shigellosis, epidemic bacillary dysentery causing bacterium. It is the dominant cause of and poses a major public health problem worldwide (Kotloff et al. 1999; Niyogi et al. 2005). People having lack of access to adequate clean drinking water, sanitation of environments, and dwelling in slums are especially at higher risk of $S$. dysenteriae's contagiousness causing a million of deaths each year (Sur et al. 2004). Few techniques have been used alongside with classic conventional culture. Immunomagnetic detection of $S$. dysenteriae type 1 and $S$. flexneri serotypes in feces has been used targeting Shigella sp. O-antigen (Islam et al. 1993) and lipopolysaccharides (Carlin and Lindberg 1987) and PCR method with primers targeting invasion plasmid antigen $\mathrm{H}$ gene sequence(ipaH gene) (Thiem et al. 2004). Duan and others used cell-SELEX to identify ssDNA MRE specific for $S$. dysenteriae. The best candidate MREs (CGGAACTA GCGTTTAAATG CCAGGACTGAAGTAGGCAGGG) had demonstrated probable low binding affinity
$(K d=23.47 \pm 2.48 \mathrm{nM})$ targeted bacteria. Fluorescent-based assay detection was carried, and results showed a LOD of $50 \mathrm{cfu} / \mathrm{mL}$. This aptamer could be employed for the capture and subsequent detection of $S$. dysenteriae from complex sample matrices and food (Duan et al. 2013b) and bears strong merits over market-dominated antibody and PCR-based technique. However, it is the only disclosed aptamer and no available aptamer-combinatorial technique used in detection of this pathogen. Furthermore, other Shigella sp. like S. sonnei is currently causing foodborne disease with shiga toxin production (Lamba et al. 2016). Our group developed a more simplified $S$. sonnei sandwich detection system. Selected aptamers Sp1 and $\mathrm{Sp} 2$ were analyzed by FACS and found to reach the sensitivity of $5.980 \pm 0.835$ and $14.32 \pm 2.19 \mathrm{nM}$, respectively. Then, both aptamers were used in a sandwich manner to capture the target. The LOD of $30 \mathrm{cfu} / \mathrm{mL}$ were achieved (Gong et al. 2015). To date, few available combinatorial aptamers are reported. At this point, aptamer-ELISA has been used with antibody as a recognition element of the target (Elham Masoudipour 2011). However, this combination approach is tedious, expensive, and requires professionalism. Therefore, it is of utmost importance to design alternative combinatorial approaches for improved detection of this pathogen.

\section{Listeria Species}

It is pathogenic bacteria Gram-positive, facultative anaerobes, rod-shaped bacteria. Its genus Listeria contains eight nonpathogenic species (L. marthii, L. innocua, L. welshimeri, L. seeligeri, L. grayi, L. rocourtiae, L. fleischmannii, and $L$. weihenstephanensis) and two pathogenic species (L. monocytogenes and L. ivanovii) which cause infection to human as well as animals (Kuenne 2010). Motility, catalase positive, and virulence are its unique features; however, little is known about its virulence. They are dispersed into the low temperature environs and most frequently in the soil, water, sewage, and foodstuffs (L. Somer 2003). The European Union in collaboration with FDA has applied a zero tolerance on L. monocytogenes in ready-to-eat food products as its rate of death is beyond C. botulinum and Salmonella spp. (CDC 2013). Although listeriosis is rare, still serious illness predominantly affects sensitive populations, i.e., infants, elders, and immunocompromised patients (Kathariou 2002). The ssDNA aptamers with binding affinity to Listeria spp. have been selected using whole-cell SELEX method, and aptamers with binding affinity were analyzed by flow cytometry. A ssDNA aptamer (LM6-116) 5'-TACTCGTTATTTCGT AGCACTTT TCCCCACCACCTTGGTG-3' binds various cell surface components (Suh et al. 2014a).

The use of SELEX to an ssDNA-conjugated biotin library is currently applied in aptamer selection and characterized with flow cytometry. The selected aptamer displayed a good binding affinity to L. monocytogenes. The selected aptamer 5'- 
GAGGGAAGAAGGGCCAGCACAGATCAGATCAA TCGCTCCG-3' conjugated to magnetic beads and when used in a combined aptamer magnetic capture (AMC)-qPCR assay: the pathogens were detected at concentrations $<60 \mathrm{cfu} / 500 \mu \mathrm{L}$ buffer in the presence of non-Listeria mixtures bacteria with a capturing efficiency of 26-77\%. This method shows a high LOD 2.7 and $4.8 \mathrm{log} \mathrm{cfu} / \mathrm{L}$ (Suh and Jaykus 2013). In another SELEX-based technique, an aptamer-A8 (5'-ATCC ATGGGGCGGAGATGAGGGGGAGGAGGGCGGGTAC CC GGTTGAT-3') specific for internalin A (L. monocytogenes invasin protein) was used in the fiber optic sensor together with antibody in a sandwich format for detection of L. monocytogenes. This selected aptamer was very selective to L. monocytogenes with quantitative detection of $\sim 10^{3} \mathrm{cfu} / \mathrm{mL}$ (Ohk et al. 2010) which is of concern due to the use of bare aptamer. For enhanced detection, a wholebacterium SELEX strategy and fluorescence-based recognition for rapid detection of $L$. monocytogenes was reported. Here, the following sequence TGGGAGCTCAG AATAAACGCTCAACTTTGTTCTTCTTGCTTTT TTTTTCTTTTTTTGTTCGACATG was modified with digoxigenin for direct fluorescent observation after combining with targeted bacteria and a fluorescent microscopy was used for direct observation of digoxigenin-aptamer binding to the target L. monocytogenes with much higher specificity (Liu Guo-qing 2014). Recently, Liu and others have shown that eight rounds of selection give ssDNA molecular recognition elements (MREs) specific for L.monocytogenes with high specificity up to $K d$ value of 60.01 nM (Liu et al. 2014). Moreover, we achieved the whole cell in vitro selection on L. monocytogenes and selected aptamer showed a considerable affinity $(K d=48.74 \pm 3.11 \mathrm{nM})$. A fluorescent binding bioassay was developed to confirm the high specific binding of these MREs towards targets demonstrated a LOD of $75 \mathrm{cfu} /$ $\mathrm{mL}$ (Duan et al. 2013a). In summary, both bare and modified aptamers have significantly contributed in improved detection of pathogens and at the same time noticeably reduced the cost incurred for detection method(s) when compared to antibodies. Despite the advantage(s) of each approach, available techniques for this pathogen are only fluorophore-aptamer-based combination rather than the use of other enhancers.

\section{Streptococcus Species}

Streptococcus species are spherical, Gram-positive bacteria belonging to Firmicutes phylum and Lactobaliales order. Many species are facultative anaerobes, catalase-negative, not motile, and occur in chains or pairs with ability to adjust at low temperature $\left(<7^{\circ} \mathrm{C}\right)$. Medically, Streptococcus species are classified depending on their hemolytic characteristics group namely alpha and beta hemolysis. They have the ability to oxidize hemoglobin iron or destroy completely red blood cells, respectively. Depending on antigenicity and physiological characteristics, Streptococcus genus is grouped into A, B, C, D, F, and G; and among them, groups A Streptococcus (GAS, with 40 antigenic species) and D (Enterococcus) can be transmitted via food. S. pyogenes possess ten major M-type surface proteins (M1, M2, M3, M4, M6, M11, M12, M28, M77, and M89) constituting its major virulence factor (Nitzsche et al. 2015). They are able to cause various infections to all individuals such as impetigo, pharyngitis, and other serious infections like necrotizing fasciitis, sepsis, and frequent GAS that may cause post-infection autoimmune diseases such as rheumatic fever, glomerulonephritis, and heart diseases which lead to high mobility and mortality (Walker et al. 2014). To date, immunodiagnosis and classic diagnosis still dominate despite tedious procedure of stool, saliva, swab, blood, and contaminated food samples culture, depicting the need of simple and fast detection techniques of these pathogens (Kim et al. 2013b). Though aptamer framework contribution in recent year increased, apparently few GAS species are studied intensely. It has been reported a combinatorial technique sensor consisting of immobilization of aptamer on SWCNTs via $\mathrm{p}$ - $\mathrm{p}$ stacking bond of ssDNA which is serially connected to $\mathrm{Au}$ electrode and piezoelectric quartz crystal. This complex is detached when the immobilized antiGAS aptamer react with GAS resulting frequency shift response because aptamer binding force to SWCNT is lower than its binding on GAS. The detected impedance spectra increased precisely to aptamer-GAS detachment with $3 \times 10^{2}$ to $3 \times 10^{6} \mathrm{cfu} / \mathrm{mL}$ concentration and the LOD of $12 \mathrm{cfu} / \mathrm{mL}$ in $40 \mathrm{~min}$ (Shi et al. 2014). However, this technique obviously could not detect targets when aptamers are dispersed or scarce since the frequency shift increased in a low range of aptamers concentration from 1 to $10 \mu \mathrm{M}$ where the increase of aptamer concentration to $12 \mu \mathrm{M}$ lowered the frequency shift due to their accumulation which can hinder the GAS recognition. Currently, Hamula and others developed targeted ten common and other ten non-common M-type $S$ .pyogenes. Bacteria were incubated with 80 nucleotide DNA libraries, and other process follows standard SELEX procedure mediated with FACS to assess the binding capacity of aptamer pool and 5' FAM labeling for visual detection. The $K d=4$ to $K d=86$ affinity range was achieved (Hamula et al. 2011). The same group improved $S$. pyogenes targeting aptamers with modification in standard SELEX. Special forward primers are designed to contain polyadenines linked to it via triethylene glycol spacer that plays a critical role in gel electrophoresis separation of both primers to the PCR product. The reverse primer was fluorescently labeled with 5' FAM to allow FACS step (Mayer et al. 2010). During incubation, selected aptamers were incubated with $S$. pyogenes, and tRNA and BSA were added in incubation buffer to increase ssDNA recognition of cell target. The modified PCR sequences, counter-selection using non-M-type cells, and finally, FACS analysis improved binding of M-type 11 protein of 
S. pyogenes with a $K d=7 \pm 1 \mathrm{nM}$ (Hamula et al. 2016). Though this binding affinity can be achieved by immunoassay-based technique, this technique is less laborious and comprehensive. Moreover, these aptamers can be fixed to solid surface for aptamer array development used in $\mathrm{M}$ typing or whole-cell detection of food or clinical samples. However, to date, no research has been reported for the other predominant $\mathrm{M}$ types of GAS, depicting the need to develop a reliable technique of detection with further modification(s) in aptamer-immunoassay combination where fluorescently labeled aptamer or antibody recognize the non-variable M-type protein of the bacteria and/or its C-terminal residues in a sandwich manner.

\section{Conclusion and Future Directives}

Aptamers were shown to be an attractive alternative to immunosensors and enzyme-based sensors for microorganisms monitoring. Those oligonucleotides are proving to be effective molecular recognition probes of high priority in food and drug quality and safety testing, disease diagnosis. etc.
They are relatively stable with ease synthesis and modification. The aptamer stability is of great importance for bacteria detection in food samples. Therefore, in near future, aptamers are promising to be antibodies other biosensors replacer in detection and diagnosis assays. Various methods based on SELEX were used for selecting aptamers with high affinity and selectivity to both small and large targets independently from their toxicity and matrix effects by influencing positively the performance and accuracy of test results. This review showed main rapid, specific, robust, and highly sensitive method approaches to select aptamers for the detection of microorganisms in foods. Although the aptamer-based assays for different targets in food are still far from guarantying complete food safety, yet, the aptamer preparation systems are facilitating the development of more reliable aptamer-based commercial devices (i.e., biosensors). Thus, we emphasized frequently used combinatorial techniques in foodborne pathogen detection. Intriguingly, all methods discussed can be used for detection of other targets by substituting the aptamer. Aptamer-conjugated nanoparticles have also showed high preference given the role of nanoparticles in stabilization of aptamer and provision of additional affinity with dissociation

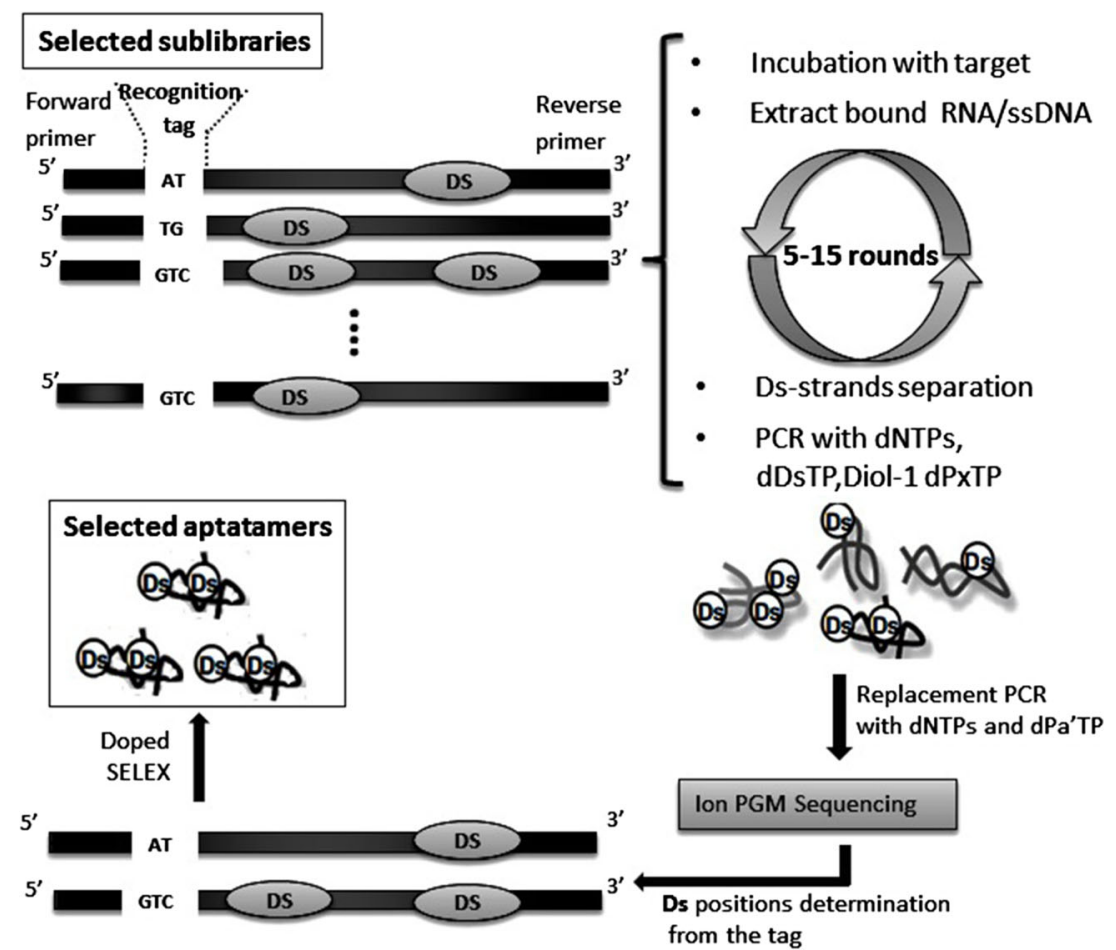

Fig. 4 Scheme of the SELEX procedure using hydrophobic unnatural base pair system for high-affinity DNA aptamer generation: The initial library is made of mixture of 22 different chemically synthesized DNA sublibraries, and each sublibrary contains 43 natural base-randomized regions with 1-3 unnatural nucleotide Ds bases at predetermined positions, flanked by constant regions of a 25-base region composed of a $5^{\prime}$ primer and a 2-3-natural base recognition tag on the $5^{\prime}$ end and a 27 base $3^{\prime}$ primer region. In each selection round, the single-stranded DNA library can be mixed with a target and the DNA fragments that bound to the target proteins extracted, followed by asymmetric PCR amplification involving the Ds-Px pair for the next round of selection. After seven rounds of selection, the enriched DNA library is PCR amplified in the presence of the natural dNTPs and the unnatural $\mathrm{dPa}^{\prime} \mathrm{TP}$ as substrates to replace the Ds bases in the DNA fragments with the natural bases (mainly $\mathrm{A}$ or T) via the Ds- $\mathrm{Pa}^{\prime}$ pair. This is followed by sequencing with Ion Torrent PGM, and then amplified DNA fragments (chemically synthesized using the natural base and Ds amidite reagents) provide the most potent aptamers towards the target(s). Finally, the selected aptamers can be optimized through doped in vitro selection to obtain the "winning" aptamers 
constant ranging from nanomolar to picomolar and LOD as low as $1-10 \mathrm{cfu} / \mathrm{mL}$. This elucidates the aptamer-nanoparticle combination ability in signal transduction which is characterized by null interference (i.e., no change in surface plasmon resonance and absorption). Furthermore, functionalization of carbon-based nanomaterials with photochromic molecules allows covalent (through cyclo-addition, condensation, or radical polymerization reaction) and non-covalent ( $\mathrm{p}-\mathrm{p}$ stacking, hydrophobic interaction, or electrostatic interaction) binding approach; hence, its combination with aptamer could be useful. However, discussed post-SELEX modifications frequently reduce aptamer affinity to the targets. The integration of chemically synthesized polynucleotide into the starting library (Fig. 4) and nanoparticle combination (Fig. 3) increase the aptamer stability but at an increased cost of the aptamer selection process. Hence, we propose combination of aptamer cocktails with nanomaterials for sensitivity enhancement and direct colorimetric visualization. This may prove promising for the development of aptamer-based techniques due to the shortage in detection of most foodborne parasites, some bacteria (e.g. all Streptococcus sp. M types except M11), viruses, and fungi towards development of feasible strips as replacer of lateral flow immunoassay for rapid detection and user friendliness. In future, leaping beyond the scope of ensuring the food safety in terms of improved detection methods, optimization of aptamer multiplex system, and whole-cell SELEX conditions may also be exploited in therapeutic arena like, but not limited to, target inhibitor aptamers or carrier aptamers of therapeutics (e.g., macular degeneration treatment) providing the insights of aptamers usage. Thus, more refinements are needed to increase aptamer and aptamer-functionalized nanoparticles and other combinatorial forms, biostability, and bioavailability to eventually tackle existing challenges.

\section{Compliance with Ethical Standards}

Conflict of Interest Omar Mukama declares that he has no conflict of interest. Jean Paul Sinumvayo declares that he has no conflict of interest. Muhammad Shamoon declares that he has no conflict of interest. Muhammad Shoaib declares that he has no conflict of interest. Henriette Mushimiyimana declares that he has no conflict of interest. Waseem Safdar declares that he has no conflict of interest. Leo Bemena declares that he has no conflict of interest. Peter Rwibasira declares that he has no conflict of interest. Samson Mugisha declares that he has no conflict of interest. Zhouping Wang declares that he has no conflict of interest.

Informed Consent Not applicable. This article does not contain any studies with human or animal subjects.

\section{References}

Abbaspour A, Norouz-Sarvestani F, Noori A, Soltani N (2015) Aptamerconjugated silver nanoparticles for electrochemical dual-aptamer- based sandwich detection of Staphylococcus aureus Biosensors and Bioelectronics 68:149-155 doi:http://dx.doi.org/10.1016/j. bios.2014.12.040

Amaya-Gonzalez S, de los Santos Alvarez N, Miranda-Ordieres AJ, Lobo-Castanon MJ (2013) Aptamer-based analysis: a promising alternative for food safety control. Sensors 13:16292-16311. doi:10.3390/s131216292

Ashley J, Ji K, Li SFY (2012) Selection of bovine catalase aptamers using non-SELEX. Electrophoresis 33:2783-2789. doi:10.1002 /elps.201200032

Baird FJ, Gasser RB, Jabbar A, Lopata AL (2014) Foodborne anisakiasis and allergy. Mol Cell Probes 28:167-174. doi:10.1016/j. mcp.2014.02.003

Bansal J, Singh I, Bhatnagar PK, Mathur PC (2013) DNA sequence detection based on Raman spectroscopy using single walled carbon nanotube. J Biosci Bioeng 115:438-441. doi:10.1016/j. jbiosc.2012.11.002

Baumstummler A, Lehmann D, Janjic N, Ochsner UA (2014) Specific capture and detection of Staphylococcus aureus with high-affinity modified aptamers to cell surface components. Lett Appl Microbiol 59:422-431. doi:10.1111/lam.12295

Beier R, Boschke E, Labudde D (2014a) New strategies for evaluation and analysis of SELEX experiments. Biomed Res Int 2014:849743. doi: $10.1155 / 2014 / 849743$

Beier R, Pahlke C, Quenzel P, Henseleit A, Boschke E, Cuniberti G, Labudde D (2014b) Selection of a DNA aptamer against norovirus capsid protein VP1. FEMS Microbiol Lett 351:162-169. doi:10.1111/1574-6968.12366

Bieke Van Dorsta JM, Bekaertb K, Martina ER, De Coena W, Dubruelc P, Blusta R, Robbensa J (2010) Recent advances in recognition elements of food and environmental biosensors. Biosens Bioelectron 26:1178-1194

Bini A, Mascini M, Mascini M, Turner AP (2011) Selection of thrombinbinding aptamers by using computational approach for aptasensor application. Biosensors \& bioelectronics 26:4411-4416. doi:10.1016/j.bios.2011.04.053

Bruno JGKJ (2002) Use of magnetic beads in selection and detection of biotoxin aptamers by electrochemiluminescence and enzymatic methods. BioTechniques 32:175-180

Bruno J (2014) Application of DNA aptamers and quantum dots to lateral flow test strips for detection of foodborne pathogens with improved sensitivity versus colloidal gold pathogens 3:341-355 doi:10.3390 /pathogens 3020341

Bruno JG, Carrillo MP, Phillips T (2008) In vitro antibacterial effects of antilipopolysaccharide DNA aptamer-C1qrs complexes. Folia Microbiol 53:295-302. doi:10.1007/s12223-008-0046-6

Bruno JG, Carrillo MP, Phillips T, Andrews CJ (2010) A novel screening method for competitive FRET-aptamers applied to E. coli assay development. J Fluoresc 20:1211-1223. doi:10.1007/s10895-010-0670-9

Bruno JG, Phillips T, Carrillo MP, Crowell R (2009) Plastic-adherent DNA aptamer-magnetic bead and quantum dot sandwich assay for Campylobacter detection. J Fluoresc 19:427-435. doi:10.1007 /s10895-008-0429-8

Cao X et al (2009) Combining use of a panel of ssDNA aptamers in the detection of Staphylococcus aureus. Nucleic Acids Res 37:46214628. doi:10.1093/nar/gkp489

Carlin NI, Lindberg AA (1987) Monoclonal antibodies specific for Shigella flexneri lipopolysaccharides: clones binding to type IV, V, and VI antigens, group 3,4 antigen, and an epitope common to all Shigella flexneri and Shigella dysenteriae type 1 stains. Infect Immun 55:1412-1420

Castro-Rosas J, Cerna-Cortes JF, Mendez-Reyes E, Lopez-Hernandez D, Gomez-Aldapa CA, Estrada-Garcia T (2012) Presence of faecal coliforms, Escherichia coli and diarrheagenic E. coli pathotypes in ready-to-eat salads, from an area where crops are irrigated with 
untreated sewage water. Int J Food Microbiol 156:176-180. doi:10.1016/j.ijfoodmicro.2012.03.025

CDC E (2013) Surveillance for foodborne disease outbreaks - United States, 1998-2008. Morb Mortal Wkly Rep 62

Chang Y-C, Yang C-Y, Sun R-L, Cheng Y-F, Kao W-C, Yang P-C (2013b) Rapid single cell detection of Staphylococcus aureus by aptamer-conjugated gold nanoparticles. Scientific Reports 3:1863. doi:10.1038/srep01863

Chang YC, Yang CY, Sun RL, Cheng YF, Kao WC, Yang PC (2013a) Rapid single cell detection of Staphylococcus aureus by aptamerconjugated gold nanoparticles. Sci Rep 3:1863. doi:10.1038/srep01863

Chen CK (2007) Complex SELEX against target mixture: stochastic computer model, simulation, and analysis. Comput Methods Prog Biomed 87:189-200. doi:10.1016/j.cmpb.2007.05.008

Cho S, Lee SH, Chung WJ, Kim YK, Lee YS, Kim BG (2004) Microbead-based affinity chromatography chip using RNA aptamer modified with photocleavable linker. Electrophoresis 25:3730 3739. doi:10.1002/elps. 200406103

Control CfD (2013) Surveillance for foodborne disease outbreaksUnited States, 1998-2008 vol 60.

Das R, Karanicolas J, Baker D (2010) Atomic accuracy in predicting and designing noncanonical RNA structure. Nat Methods 7:291-294. doi:10.1038/nmeth.1433

DeGrasse JA (2012a) A single-stranded DNA aptamer that selectively binds to Staphylococcus aureus enterotoxin B. PLoS One 7: e33410. doi:10.1371/journal.pone.0033410

DeGrasse JA (2012b) A single-stranded DNA aptamer that selectively binds to Staphylococcus aureus enterotoxin B. PLoS One 7:7. doi:10.1371/journal.pone. 0033410

Drabovich A (2009) Aptamers in bioanalysis. John Wiley \& Sons, Inc.

Drobniewski FA (1993) Bacillus cereus and related species. Clin Microbiol Rev 6:324-338

Duan N, Ding X, He L, Wu S, Wei Y, Wang Z (2013a) Selection, identification and application of a DNA aptamer against Listeria monocytogenes. Food Control 33:239-243. doi:10.1016/j. foodcont.2013.03.011

Duan N, Ding X, Wu S, Xia Y, Ma X, Wang Z, Chen J (2013b) In vitro selection of a DNA aptamer targeted against Shigella dysenteriae. J Microbiol Methods 94:170-174. doi:10.1016/j.mimet.2013.06.016

Duan N, Wu S, Chen X, Huang Y, Xia Y, Ma X, Wang Z (2013c) Selection and characterization of aptamers against Salmonella typhimurium using whole-bacterium Systemic Evolution of Ligands by Exponential Enrichment (SELEX). J Agric Food Chem 61:3229-3234. doi:10.1021/jf400767d

Duan N, Chang B, Zhang H, Wang Z, Wu S (2016) Salmonella tymphimurium detection using a surface-enhanced raman scattering based aptasensor. Int J Food Microbiol 218:38-43. doi:10.1016/j. ijfoodmicro.2015.11.006

Duan N et al (2013d) A dual-color flow cytometry protocol for the simultaneous detection of Vibrio parahaemolyticus and Salmonella typhimurium using aptamer conjugated quantum dots as labels. Anal Chim Acta 804:151-158. doi:10.1016/j.aca.2013.09.047

Dwivedi HP, Smiley RD, Jaykus LA (2013) Selection of DNA aptamers for capture and detection of Salmonella typhimurium using a whole-cell SELEX approach in conjunction with cell sorting. Appl Microbiol Biotechnol 97:3677-3686. doi:10.1007/s00253-013-4766-4

Dwivedi H, Smiley RD, Jaykus L-A (2010a) Selection and characterization of DNA aptamers with binding selectivity to Campylobacter jejuni using whole-cell SELEX. Appl Microbiol Biotechnol 87: 2323-2334. doi:10.1007/s00253-010-2728-7

Dwivedi HP, Smiley RD, Jaykus L-A (2010b) Selection and characterization of DNA aptamers with binding selectivity to Campylobacter jejuni using whole-cell SELEX. Appl Microbiol Biotechnol 87: 2323-2334. doi:10.1007/s00253-010-2728-7
Elham Masoudipour SLM, Basiri M (2011) Specific detection of Shigella sonnei by enzyme-linked aptamer sedimentation assay. Progress in Biological Sciences 1:11-15

Elham Masoudipour, Seyed Latif Mousavi, Basiri M (2011) Specific detection of Shigella sonnei by enzyme-linked aptamer sedimentation assay Progress in Biological Sciences 1

Escudero-Abarca BI, Suh SH, Moore MD, Dwivedi HP, Jaykus LA (2014) Selection, characterization and application of nucleic acid aptamers for the capture and detection of human norovirus strains. PLoS One 9:106805. doi:10.1371/journal.pone.0106805

Fan M, McBurnett SR, Andrews CJ, Allman AM, Bruno JG, Kiel JL (2008) Aptamer selection express: a novel method for rapid singlestep selection and sensing of aptamers. Journal of Biomolecular Techniques : JBT 19:311-319

Feng H, Beck J, Nassal M, Hu KH (2011) A SELEX-screened aptamer of human hepatitis B virus RNA encapsidation signal suppresses viral replication. PLoS One 6:27862. doi:10.1371/journal.pone.0027862

Fernandez PP (2006) Selection of an aptamer against surface exposed targets on yersinia pestis. Oklahoma State University, Research

Florian Jarosch KB, Klussmann S (2006) In vitro selection using a dual RNA library that allows primerless selection. Nucleic Acids Res 34:86

Giamberardino A et al (2013) Ultrasensitive norovirus detection using DNA aptasensor technology. PLoS One 8:e79087. doi:10.1371 /journal.pone.0079087

Gong W, Duan N, Wu S, Huang Y, Chen X, Wang Z (2015) Selection, identification, and application of dual DNA aptamers against Shigella sonnei. Anal Methods 7:3625-3631. doi:10.1039/C5 AY00214A

Hamula C, Guthrie J, Zhang H, Li X, Le X (2006) Selection and analytical applications of aptamers. TrAC Trends Anal Chem 25:681-691. doi:10.1016/j.trac.2006.05.007

Hamula CL, Le XC, Li XF (2011) DNA aptamers binding to multiple prevalent M-types of Streptococcus pyogenes. Anal Chem 83: 3640-3647. doi:10.1021/ac200575e

Hamula CLA, Peng H, Wang Z, Tyrrell GJ, Li X-F, Le XC (2016) An improved SELEX technique for selection of DNA aptamers binding to M-type 11 of Streptococcus pyogenes. Methods 97:51-57. doi:10.1016/j.ymeth.2015.12.005

Hamula CL, Zhang H, Guan LL, Li XF, Le XC (2008) Selection of aptamers against live bacterial cells. Anal Chem 80:7812-7819. doi:10.1021/ac801272s

Han SR, Lee SW (2013) In vitro selection of RNA aptamer specific to Salmonella typhimurium. J Microbiol Biotechnol 23:878-884. doi:10.4014/jmb.1212.12033

Hayat A, Andreescu S, Marty JL (2013) Design of PEG-aptamer two piece macromolecules as convenient and integrated sensing platform: application to the label free detection of small size molecules. Biosensors \& bioelectronics 45:168-173. doi:10.1016/j. bios.2013.01.059

Helgason EOO, Caugant D et al (2000) Bacillus anthracis, Bacillus cereus and Bacillus thuringiensis - one species on the basis of genetic evidence. Appl Environ Microbiol 66:2627-2630

Hernández R, Vallés C, Benito AM, Maser WK, Xavier Rius F, Riu J (2014) Graphene-based potentiometric biosensor for the immediate detection of living bacteria. Biosens Bioelectron 54:553-557. doi:10.1016/j.bios.2013.11.053

Huang YK, Chen XJ, Xia Y, Wu SJ, Duan N, Ma XY, Wang ZP (2014) Selection, identification and application of a DNA aptamer against Staphylococcus aureus enterotoxin a. Anal Methods 6:690-697. doi:10.1039/c3ay41576g

Huenniger T, Wessels H, Fischer C, Paschke-Kratzin A, Fischer M (2014) Just in time-selection: a rapid semiautomated SELEX of DNA aptamers using magnetic separation and BEAMing. Anal Chem 86:10940-10947. doi:10.1021/ac503261b 
Ikanovic M et al (2007) Fluorescence assay based on aptamer-quantum dot binding to Bacillus thuringiensis spores. J Fluoresc 17:193-199. doi:10.1007/s10895-007-0158-4

Iqbal A, Labib M, Muharemagic D, Sattar S, Dixon BR, Berezovski MV (2015) Detection of Cryptosporidium parvum oocysts on fresh produce using DNA aptamers. PLoS One 10:0137455. doi:10.1371 journal.pone. 0137455

Islam D, Tzipori S, Islam M, Lindberg AA (1993) Rapid detection of Shigella dysenteriae and Shigella flexneri in faeces by an immunomagnetic assay with monoclonal antibodies European. journal of clinical microbiology \& infectious diseases : official publication of the European Society of Clinical Microbiology 12:25-32

Jay HPDRDSL-A (2013) Selection of DNA aptamers for capture and detection of SalmonellaTyphimurium using a whole-cell SELEX approach in conjunction with cell sorting. Appl Microbiol Biotechnol 97:677-3686

Jaykus HPDRDSL-A (2010) Selection and characterization of DNA aptamers with binding selectivity toCampylobacter jejuni using whole-cell SELEX. Appl Microbiol Biotechnol 87:2323-2334

Kasahara Y, Irisawa Y, Ozaki H, Obika S, Kuwahara M (2013) 2',4'BNA/LNA aptamers: CE-SELEX using a DNA-based library of full-length 2'-O,4'-C-methylene-bridged/linked bicyclic ribonucleotides. Bioorg Med Chem Lett 23:1288-1292. doi:10.1016/j. bmcl.2012.12.093

Kathariou S, Food Prot J (2002) Listeria monocytogenesvirulence and pathogenicity, a food safety perspective. J Food Prot 65:1811-1829

Keefe AD, Cload ST (2008) SELEX with modified nucleotides. Curr Opin Chem Biol 12:448-456. doi:10.1016/j.cbpa.2008.06.028

Kim YS, Gu MB (2014) Advances in aptamer screening and small molecule aptasensors. Adv Biochem Eng Biotechnol 140:29-67. doi:10.1007/10 2013225

Kim MA, Jeon HS, Shin SY, Baik BJ, Yang YM, Lee KY, Kim JG (2013b) Rapid detection of S. mutans surface antigen I/II using a sensitive monoclonal anti-Ag I/II antibody by ELISA. Monoclonal antibodies in immunodiagnosis and immunotherapy 32:336-340. doi:10.1089/mab.2013.0017

Kim YS, Song MY, Jurng J, Kim BC (2013c) Isolation and characterization of DNA aptamers against Escherichia coli using a bacterial cellsystematic evolution of ligands by exponential enrichment approach. Anal Biochem 436:22-28. doi:10.1016/j.ab.2013.01.014

Kim L, Yu H-W, Kim Y-H, Kim I, Jang A (2013a) Potential of fluorophore labeled aptamers for Pseudomonas Aeruginosa detection in drinking water. J Korean Soc Appl Biol Chem 56:165-171. doi:10.1007/s13765-013-3019-7

Kim YS, Chung J, Song MY, Jurng J, Kim BC (2014) Aptamer cocktails: enhancement of sensing signals compared to single use of aptamers for detection of bacteria. Biosens Bioelectron 54:195-198. doi:10.1016/j.bios.2013.11.003

Kimoto M, Yamashige R, Matsunaga K, Yokoyama S, Hirao I (2013) Generation of high-affinity DNA aptamers using an expanded genetic alphabet. Nat Biotechnol 31:453-457. doi:10.1038/nbt.2556

King NJ, Whyte R, Hudson JA (2007) Presence and significance of Bacillus cereus in dehydrated potato products. J Food Prot 70: 514-520

Klussmann S, Nolte A, Bald R, Erdmann VA, Furste JP (1996) Mirrorimage RNA that binds D-adenosine. Nat Biotechnol 14:1112-1115. doi:10.1038/nbt0996-1112

Kopylov AM, Spiridonova VA (2000) Combinatorial chemistry of nucleic acids: SELEX. Mol Biol 34:940-954. doi:10.1023/a:1026696330245

Kotaro Fukuda DV, Sekiya S, Hwang J, Kakiuchi N, Taira K, Shimotohno K, Kumar PKR, Nishikawa S (2003) Isolation and characterization of RNA aptamers specific for hepatitis C virus nonstructural proteins 3 protease issue. Eur J Biochem 267:3685-3694

Kotloff KL, Winickoff JP, Ivanoff B, Clemens JD, Swerdlow DL, Sansonetti PJ et al (1999) Global burden of Shigella infections: implications for vaccine development and implementation of control strategies. Bull World Health Organ 77:651-666

Kuenne C, Vogets S, Pischimarov J, Oehm S, Goesmann A, Daniel R, Hain T, Chakraborty T (2010) Comparative analysis of plasmids in the genus Listeria. PLoS One 5:12511

Kulbachinskiy AV (2007) Methods for selection of aptamers to protein targets. Biochem Mosc 72:1505-1518. doi:10.1134 /s000629790713007x

Lamba K et al (2016) Shiga toxin 1-producing Shigella sonnei infections, California, United States, 2014-2015. Emerg Infect Dis 22:679-686. doi:10.3201/eid2204.151825

Lee CH, Lee SH, Kim JH, Noh YH, Noh GJ, Lee SW (2015) Pharmacokinetics of a cholesterol-conjugated aptamer against the hepatitis $\mathrm{C}$ virus (HCV) NS5B. Protein Mol Ther Nucleic Acids 4: e254. doi:10.1038/mtna.2015.30

Li K, Lai Y, Zhang W, Jin L (2011) Fe2O3@Au core/shell nanoparticlebased electrochemical DNA biosensor for Escherichia coli detection. Talanta 84:607-613. doi:10.1016/j.talanta.2010.12.042

Lim YC, Kouzani AZ, Duan W (2010) Aptasensors: a review. J Biomed Nanotechnol 6:93-105

Lin H, Zhang W, Jia S, Guan Z, Yang CJ, Zhu Z (2014) Microfluidic approaches to rapid and efficient aptamer selection Biomicrofluidics 8 doi:10.1063/1.4890542

Litao Yang CWF, Cho EJ, Ellington AD (2007) Real-time rolling circle amplification for protein detection. Anal Chem 79:3320-3329

Liu Guo-qing LY-Q, Chao G, Xiao-feng Y, Ming Z, Kai Z, Xuejiao C, Yi $Y$ (2014) In vitro selection of DNA aptamers and fluorescencebased recognition for rapid detection Listeria monocytogenes. J Integr Agric 13:1121-1129

Liu G-Q et al (2014) In vitro selection of DNA aptamers and fluorescencebased recognition for rapid detection Listeria monocytogenes. J Integr Agric 13:1121-1129. doi:10.1016/s2095-3119(14)60766-8

Lu E, Elizondo-Riojas M-A, Chang JT, Volk DE (2014) Aptaligner: automated software for aligning pseudorandom DNA X-aptamers from next-generation sequencing data. Biochemistry 53:35233525. doi:10.1021/bi500443e

Ma X, Jiang Y, Jia F, Yu Y, Chen J, Wang Z (2014) An aptamer-based electrochemical biosensor for the detection of Salmonella. J Microbiol Methods 98:94-98. doi:10.1016/j.mimet.2014.01.003

Martell RE, Nevins JR, Sullenger BA (2002) Optimizing aptamer activity for gene therapy applications using expression cassette SELEX. Mol Ther 6:30-34. doi:10.1006/mthe.2002.0624

Marty JL Hayat A (2014) Aptamer based electrochemical sensors for emerging environmental pollutants Front Chem 2

Mathew A, Maekawa T, Sakthikumar D (2015) Aptamers in targeted nanotherapy Current Topics in Medicinal Chemistry 15:1102-1114

Mayer G, Ahmed M-SL, Dolf A, Endl E, Knolle PA, Famulok M (2010) Fluorescence-activated cell sorting for aptamer SELEX with cell mixtures. Nat Protocols 5:1993-2004

McKeague M, Derosa MC (2012) Challenges and opportunities for small molecule aptamer development. Journal of nucleic acids 2012:748 913. doi:10.1155/2012/748913

McKeague M, Giamberardino A (2011) Advances in aptamer-based biosensors for food safety. Somerset (Ed.) edn. InTech,

McKeague M, Giamberardino A, DeRosa CM (2011) Advances in aptamerbased biosensors for food safety. In: Somerset V (ed). Carleton University, Department of Chemistry Ottawa, Ontario,canada,

McKeague M, Velu R, Hill K, Bardoczy V, Meszaros T, MC DR (2014) Selection and characterization of a novel DNA aptamer for labelfree fluorescence biosensing of ochratoxin A. Toxins 6:2435-2452. doi: $10.3390 /$ toxins 6082435

Mei ZM, Chu HQ, Chen W, Xue F, Liu J, Xu HN, Zhang R, Zheng L (2013) Ultrasensitive one-step rapid visual detection of bisphenol A in water samples by label-free aptasensor. Biosensors \& bioelectronics 39:26-30 
Ming Yang ZP, Ning Y, Chen Y, Zhou Q, Deng L (2013) Highly specific and cost-efficient detection of Salmonella Paratyphi A combining aptamers with single-walled carbon. Nanotubes Sensors 13:6865-6881

Moon J, Kim G, Lee S, Park S (2013) Identification of Salmonella Typhimurium-specific DNA aptamers developed using whole-cell SELEX and FACS analysis. J Microbiol Methods 95:162-166. doi:10.1016/j.mimet.2013.08.005

Moon J, Kim G, Park S (2014) Development of ssDNA aptamers for the capture and detection of Salmonella typhimurium. Anal Methods 6: 7442-7448. doi:10.1039/c4ay01035c

Moon J, Kim G, Park SB, Lim J, Mo C (2015) Comparison of whole-cell SELEX methods for the identification of Staphylococcus aureus-specific DNA aptamers. Sensors 15:8884-8897. doi:10.3390/s150408884

Mossali C et al (2010) Sensitive detection and quantification of anisakid parasite residues in food products. Foodborne Pathog Dis 7:391397. doi:10.1089/fpd.2009.0428

Nitzsche R, Rosenheinrich M, Kreikemeyer B, Oehmcke-Hecht S (2015) Streptococcus pyogenes triggers activation of the human contact system by streptokinase. Infect Immun 83:3035-3042. doi:10.1128/IAI.00180-15

Niyogi, SK, (2005) Shigellosis J Microbiol: 133-143

Nonaka Y, Yoshida W, Abe K, Ferri S, Schulze H, Bachmann TT, Ikebukuro K (2013) Affinity improvement of a VEGF aptamer by in silico maturation for a sensitive VEGF-detection system. Anal Chem 85:1132-1137. doi:10.1021/ac303023d

Ohk SH, Koo OK, Sen T, Yamamoto CM, Bhunia AK (2010) Antibodyaptamer functionalized fibre-optic biosensor for specific detection of Listeria monocytogenes from food. J Appl Microbiol 109:808-817. doi:10.1111/j.1365-2672.2010.04709.x

Ohuchi SP, Ohtsu T, Nakamura Y (2006) Selection of RNA aptamers against recombinant transforming growth factor-beta type III receptor displayed on cell surface. Biochimie 88:897-904. doi:10.1016/j. biochi.2006.02.004

Park H-C, Baig I, Lee S-C, Moon J-Y, Yoon M-Y (2014a) Development of ssDNA aptamers for the sensitive detection of Salmonella typhimurium and Salmonella enteritidis. Appl Biochem Biotechnol 174:793-802. doi:10.1007/s12010-014-1103-Z

Park H-C, Baig IA, Lee S-C, Moon J-Y, Yoon M-Y (2014b) Development of ssDNA aptamers for the sensitive detection of Salmonella typhimurium and Salmonella enteritidis. Appl Biochem Biotechnol 174:793-802. doi:10.1007/s12010-014-1103-Z

Radi A-E (2011) Electrochemical aptamer-based biosensors. Recent Advances and Perspectives International Journal of Electrochemistry 2011:1-17. doi:10.4061/2011/863196

Raghavendra Joshi HJ, Hari P, Dwivedi TMA, Kumar S, Jayku L-A, Schefers J, Sreevatsan S (2009) Selection, characterization, and application of DNA aptamers for the capture and detection ofSalmonella entericaserovars. Mol Cell Probes 23:20-28

Savory N et al (2013) In silico maturation of binding-specificity of DNA aptamers against Proteus mirabilis. Biotechnol Bioeng 110:25732580. doi:10.1002/bit.24922

Scognamiglio V, Arduini F, Palleschi G, Rea G (2014) Biosensing technology for sustainable food safety. TrAC Trends Anal Chem 62:110. doi:10.1016/j.trac.2014.07.007

Sett A (2012) Aptasensors in health. Environment and Food Safety Monitoring Open Journal of Applied Biosensor 01:9-19. doi:10.4236/ojab.2012.12002

Shi X, He F, Lian Y, Yan D, Zhang X (2014) A new aptamer/SWNTs IDE-SPQC sensor for rapid and specific detection of Group A Streptococcus. Sensors and Actuators B: Chemical 198:431-437. doi:10.1016/j.snb.2014.03.067

So HM et al. (2008) Detection and titer estimation of Escherichia coli using aptamer-functionalized single-walled carbon-nanotube fieldeffect transistors Small 4:197-201
Somer L, Kashi Y (2003) A PCR method based on 16S rRNA sequence for simultaneous detection of the genus listeria and the species Listeria monocytogenesin food products. J Food Prot 66:1658-1665

Spiridonova LN (2014) Introgression of nuclear and mitochondrial DNA markers of Mus musculus musculus to aboriginal populations of wild mice from Central Asia (M-m. wagneri) and South Siberia (M-m. gansuensis). Mol Biol 48:75-83. doi:10.1134/s0026893314010142

Spiridonova VA, Levashov PA, Ovchinnikova ED, Afanasieva OI, Glinkina KA, Adamova IY, Pokrovsky SN (2014) DNA aptamer-based sorbents for binding human IgE. Russian Journal of Bioorganic Chemistry 40: 151-154. doi:10.1134/s1068162014020125

Stoltenburg R, Reinemann C, Strehlitz B (2005b) FluMag-SELEX as an advantageous method for DNA aptamer selection. Anal Bioanal Chem 383:83-91. doi:10.1007/s00216-005-3388-9

Stoltenburg R, Reinemann C, Strehlitz B (2005a) FluMag-SELEX as an advantageous method for DNA aptamer selection. Anal Bioanal Chem 383:83-91. doi:10.1007/s00216-005-3388-9

Stoltenburg R, Reinemann C, Strehlitz B (2007) SELE-a (r)evolutionary method to generate high-affinity nucleic acid ligands. Biomol Eng 24:381-403. doi:10.1016/j.bioeng.2007.06.001

Stratis-Cullum DN, McMasters S, Pellegrino PM (2009) Evaluation of relative aptamer binding to campylobacter jejuni bacteria using affinity probe capillary electrophoresis. Anal Lett 42:2389-2402. doi:10.1080/00032710903137376

Subramanian Viswanathan JR (2008) Nanomaterials in electrochemical biosensors for food analysis - a review food and nutrition sciences 58:157-164

Suh SH, Jaykus L-A (2013) Nucleic acid aptamers for capture and detection of Listeria spp. J Biotechnol 167:454-461. doi:10.1016/j. jbiotec.2013.07.027

Suh SH, Dwivedi HP, Jaykus L-A (2014b) Development and evaluation of aptamer magnetic capture assay in conjunction with real-time PCR for detection of Campylobacter jejuni. LWT Food Sci Technol 56:256-260. doi:10.1016/j.lwt.2013.12.012

Suh SH, Dwivedi HP, Choi SJ, Jaykus LA (2014a) Selection and characterization of DNA aptamers specific for Listeria species. Anal Biochem 459:39-45. doi:10.1016/j.ab.2014.05.006

Sur DS, Ramamurthy T, Deen J, Bhattarcharya SK et al (2004) Shigellosis: challenges and management issues. Indian J Med 120: 454-462

Thiel KW, Giangrande PH (2009) Therapeutic applications of DNA and RNA aptamers. Oligonucleotides 19:209-222. doi:10.1089 /oli.2009.0199

Thiem VD et al (2004) Detection of Shigella by a PCR assay targeting the ipaH gene suggests increased prevalence of shigellosis in Nha Trang, Vietnam. Journal of Clinical Microbiology 42:2031-2035. doi:10.1128/JCM.42.5.2031-2035.2004

Tibor Hianik VO, Sonlajtnerova M, Grman I (2007) Influence of ionic strength, $\mathrm{pH}$ and aptamer configuration for binding affinity to thrombin. bielectrochemistry 70:127-133

Tombelli SMM, Mascini M (2007) Aptamers-based assays for diagnostics, environmental and food analysis. Biomol Eng 24:191-200

Tombelli S, Minunni M, Mascini M (2007) Aptamers-based assays for diagnostics, environmental and food analysis. Biomol Eng 24:191200. doi:10.1016/j.bioeng.2007.03.003

Torres-Chavolla E, Alocilja EC (2009) Aptasensors for detection of microbial and viral pathogens. Biosensors \& bioelectronics 24:31753182. doi:10.1016/j.bios.2008.11.010

Tuerk CALG (1990a) Systematic evolution of ligands by exponential enrichment: RNA ligands to bacteriophage T4 DNA polymerase. BioTechniques. doi:10.2144/000113786

Tuerk CALG (1990b) Systematic evolution of ligands by exponential enrichment: RNA ligands to bacteriophage T4 DNA polymerase. BioTechniques 249:505-510. doi:10.2144/000113786

Velusamy V, Arshak K, Korostynska O, Oliwa K, Adley C (2010) An overview of foodborne pathogen detection: in the perspective of 
biosensors. Biotechnol Adv 28:232-254. doi:10.1016/j. biotechadv.2009.12.004

Walker MJ et al (2014) Disease manifestations and pathogenic mechanisms of Group A Streptococcus. Clin Microbiol Rev 27:264-301. doi:10.1128/CMR.00101-13

Wang Y-X, Ye Z-Z, Si C-Y, Ying Y-B (2012) Application of aptamer based biosensors for detection of pathogenic microorganisms. Chin J Anal Chem 40:634-642. doi:10.1016/s18722040(11)60542-2

Wang KY, Zeng YL, Yang XY, Li WB, Lan XP (2011) Utility of aptamerfluorescence in situ hybridization for rapid detection of Pseudomonas aeruginosa. Eur J Clin Microbiol Infect Dis 30:273278. doi:10.1007/s10096-010-1074-0

Warda AK et al (2016) Linking Bacillus cereus genotypes and carbohydrate utilization capacity. PLoS One 11:e0156796. doi:10.1371/journal.pone.0156796

Wei Wu ZF, Zhaoa S, Lua X, Yua L, Meia T, Zeng L (2015) A simple aptamer biosensor for Salmonellae enteritidis based on fluorescence-switch signaling graphene oxide. RSC Adv 4:2200922012. doi:10.1039/b000000x

Wenhe Wu JZ, Zheng M, Zhong Y, Yang J, Zhao Y, Wu W, Wei Ye JW, Wang Q, Lu J (2012) An aptamer-based biosensor for colorimetric detection of Escherichia coli O157:H7. PLoS One 7:9. doi:10.1371/journal.pone.0048999.g002

Wu LH, Curran JF (1999) An allosteric synthetic DNA. Nucleic Acids Research 27:1512-1516. doi:10.1093/nar/27.6.1512

Wu S, Duan N, Shi Z, Fang C, Wang Z (2014) Simultaneous aptasensor for multiplex pathogenic bacteria detection based on multicolor upconversion nanoparticles labels. Anal Chem 86:3100-3107. doi: $10.1021 / \mathrm{ac} 404205 \mathrm{c}$

Xi Z, Huang R, Deng Y, He N (2014) Progress in selection and biomedical applications of aptamers. J Biomed Nanotechnol 10:3043-3062

Xu D-M, Wu M, Zou Y, Zhang Q, Wu C-C, Zhou Y, Liu X-J (2011) Application of aptamers in food safety. Chin J Anal Chem 39:925933. doi:10.1016/s1872-2040(10)60447-1
Yang X-H, Kong W-J, Yang M-H, Zhao M, Ouyang Z (2013) Application of aptamer identification technology in rapid analysis of mycotoxins. Chin J Anal Chem 41:297-306. doi:10.1016/s1872-2040 (13)60630-1

Yuan J, Tao Z, Yu Y, Ma X, Xia Y, Wang L, Wang Z (2014) A visual detection method for Salmonella Typhimurium based on aptamer recognition and nanogold labeling. Food Control 37:188-192. doi:10.1016/j.foodcont.2013.09.046

Yun W, Li H, Chen S, Tu D, Xie W, Huang Y (2014) Aptamer-based rapid visual biosensing of melamine in whole milk. Eur Food Res Technol 238:989-995. doi:10.1007/s00217-014-2166-3

Zelada-Guillén GA, Bhosale SV, Riu J, Rius FX (2010) Real-time potentiometric detection of bacteria in complex samples. Anal Chem 82: 9254-9260. doi:10.1021/ac101739b

Zhang X, Du X-J, Guan C, Li P, Zheng W-J, Wang S (2015) Detection of Vibrio cholerae by isothermal cross-priming amplification combined with nucleic acid detection strip analysis. Mol Cell Probes 29:208-214. doi:10.1016/j.mcp.2015.05.001

Zhijun Guoa JR, Wanga J, Wanga E (2011) Single-walled carbon nanotubes based quenching of free FAM-aptamer for selective determination of ochratoxin A. Talanta 85:2517-2521

Zhou L, Wang M-H, Wang J-P, Ye Z-Z (2011) Application of biosensor surface immobilization methods for aptamer Chinese. J Anal Chem 39:432-438. doi:10.1016/s1872-2040(10)60429-x

Zimmermann B, Bilusic I, Lorenz C, Schroeder R (2010) Genomic SELEX: a discovery tool for genomic aptamers. Methods (San Diego, Calif) 52:125-132. doi:10.1016/j. ymeth.2010.06.004

Zuo PLX, Dominguez DC, Ye BC (2013) A PDMS/paper/glass hybrid microfluidic biochip integrated with aptamer-functionalized graphene oxide nano-biosensors for one-step multiplexed pathogen detection. Biosensor Bioelectron 13:3921-3928 